\title{
Photoionization of Atmospheric Aerosol Constituents and Precursors in the 7-15 eV Energy Region: Experimental and Theoretical Study
}

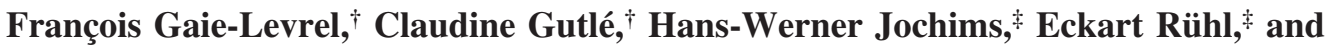 \\ Martin Schwell*, \\ Laboratoire Interuniversitaire des Systèmes Atmosphériques (LISA), Universités Paris 12 et Paris 7, UMR 7583 du \\ CNRS, 61 avenue du Général de Gaulle, 94010 Créteil cedex, France, and Physikalische und Theoretische Chemie, \\ Institut für Chemie und Biochemie, Freie Universität Berlin, Takustrasse 3, 14195 Berlin, Germany
}

Received: December 20, 2007; Revised Manuscript Received: March 5, 2008

\begin{abstract}
Photoionization mass spectrometry (PIMS) has been used to study the dissociative ionization of three anthropogenic atmospheric aerosol precursors (o-xylene, 2-methylstyrene, indene) and five of their main atmospheric degradation products (o-tolualdehyde, 2-methylphenol, $o$-toluic acid, phthalic acid, and phthaldialdehyde). Ionization and fragment appearance energies have been experimentally determined in the $7-15 \mathrm{eV}$ photon energy regime. Moreover, intensive ab inito quantum chemical calculations have been performed to compute the first ionization energies and heats of formation of these compounds (including also phthalic anhydride). Several methods have been used, and the theoretical results are compared to the experimental values with the aim to find the best method to predict thermochemical data for similar molecules. The vacuum-UV fragmentation pathways following photoionization are discussed. The results of this work are important with respect to the analytical chemistry of these compounds since their basic gas phase ion energetics data are mostly unknown. They will help in interpreting real-time mass spectrometric measurements used for the study of organic aerosol formation in smog chambers and in the real atmosphere.
\end{abstract}

\section{Introduction}

Atmospheric aerosols are important species with respect to their impact on the radiative forcing on the Earth's climate system. ${ }^{1}$ Due to the 2007 report of the Working group 1 of the Intergovernmental Panel on Climate Change (IPCC), which summarizes current understanding of the radiative budget of the atmosphere, the sum of direct and indirect effects is on the same order of magnitude compared to the $\mathrm{CO}_{2}$ radiative forcing $\left(1.7 \mathrm{~W} \mathrm{~m}^{-2}\right)$, but with the opposite sign. ${ }^{2}$ Large uncertainties persist in the aerosol effect, on the order of $0.8 \mathrm{~W} \mathrm{~m}^{-2}$ for the direct effect and about $1.5 \mathrm{~W} \mathrm{~m}^{-2}$ for the indirect effect.

Both effects on the climate depend on the complex chemical composition of the aerosols, which contain numerous compounds in extremely variable mixing ratios. Significant amounts of particulate matter are organic in nature, but this fraction is far from being fully characterized. Organic aerosols (OA) can contribute $20-50 \%$ of the total fine aerosol mass in continental midlatitudes ${ }^{3}$ and up to $90 \%$ in tropical highly forested areas or urban areas. ${ }^{4} \mathrm{OA}$ can be separated into primary organic aerosols (POA) and secondary organic aerosols (SOA). POA are directly emitted to the atmosphere and their sources are mainly biomass burning and combustion processes, ${ }^{5}$ whereas SOA are produced from volatile organic compounds (VOCs) in the atmosphere by different oxidation mechanisms. Biogenic VOCs, such as isoprene, monoterpenes, and sesquiterpenes, are the major precursors of biogenic SOA on a global scale. ${ }^{6}$ An estimation of the global annual production from biogenic VOCs ranges from 2.5 to $44.5 \mathrm{Tg}_{\text {year }}{ }^{-1}$ organic matter, whereas the production from anthropogenic VOCs (AVOCs) ranges from

* Corresponding author. Telephone: +33 14517 1521. Fax: +33 14517 1564. E-mail: schwell@lisa.univ-paris12.fr.

${ }^{\dagger}$ Universités Paris 12 et Paris 7.

${ }^{\ddagger}$ Freie Universität Berlin.
0.05 to $2.62 \mathrm{Tg}$ year ${ }^{-1} .{ }^{7}$ However, due to results from recent field studies, the total amount of anthropogenic SOA (ASOA) in our atmosphere is probably underestimated. ${ }^{8}$ Indeed, AVOCs such as alkenes, carbonyls, and most frequently aromatic hydrocarbons represent a significant fraction of the organic gas phase component, especially in the polluted urban atmosphere. These compounds can form ASOA following oxidation reactions.

SOA formation has been widely studied in past years, both in the field ${ }^{8,9}$ and in the laboratory ${ }^{10,11}$ where smog chambers are commonly used. Recently, online aerosol mass spectrometry techniques have also been employed to chemically analyze SOA particles. ${ }^{12,13}$ They integrate aerosol sampling, particle sizing, and chemical analysis. Some of them operate with single or resonant photoionization (SPI or RPI) using monochromatic radiation obtained from lasers, at photon energies between 5 and $10.5 \mathrm{eV} \cdot{ }^{14-17} \mathrm{We}$ also note that synchrotron radiation has been used to characterize model aerosol particles consisting of pure substances ${ }^{18}$ and binary mixtures. ${ }^{19}$

When analyzing the online mass spectra of complex mixtures, such as freshly formed SOA particles, it is often very difficult to assign a particular mass peak. Notably, it can be problematical to distinguish between parent and fragment ions. Furthermore, it appears that basic gas phase ion energetics data are often unknown for important compounds involved in SOA chemistry. The limited literature data available, mainly from electron impact mass spectrometric measurements (EIMS) or from photoelectron spectroscopy (PES), suffer often from unsatisfactory accuracy and poor detection sensitivity, resulting in too-high ionization energies (IEs) and too-high fragment appearance energies (AEs), sometimes also together with large experimental error limits. However, accurate data are needed to interpret photoionization mass spectra from experiments relying on monochromatic radiation. 


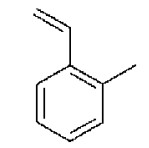

Methylstyrene
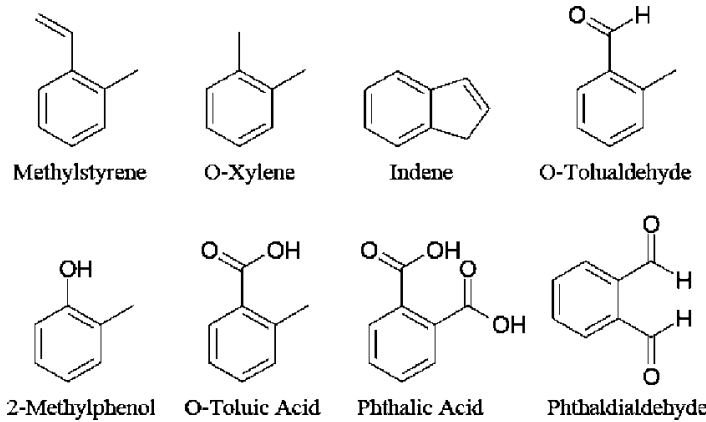

Figure 1. Anthropogenic volatile organic compounds (AVOCs) and associated degradation products investigated in this study.

In this paper, we report results of a photoionization mass spectrometry (PIMS) study of three AVOCs: $o$-xylene, 2-methylstyrene, and indene. Furthermore, five major atmospheric degradation products of these compounds, $o$-tolualdehyde, 2-methylphenol, $o$-toluic acid, phthalic acid, and phthaldialdehyde, respectively, have been studied (see Figure 1). Synchrotron radiation has been used to measure photoion yield curves of parent and selected fragment ions as a function of the incident photon energy in the $7-15 \mathrm{eV}$ regime. Properties such as IEs and fragment AEs are determined. This technique has been used in the past and has been proven to yield reliable gas phase ion energetics data, even for low volatile compounds. ${ }^{20}$

At the same time an effort has been put into the ab initio quantum chemical calculation of the first ionization energies and heats of formation $\left(\Delta_{\mathrm{f}} H\right)$ of these compounds, in order to be able to predict reliably relevant IEs and $\Delta_{\mathrm{f}} H$ values for similar molecules. We also included phthalic anhydride in the calculations. This compound represents a chemically related molecule which was not studied experimentally.

All the data, experimental and theoretical, will help to analyze vacuum-ultraviolet (VUV) radiation induced ionization and fragmentation pathways of the formed cations. They thus will facilitate comprehension and interpretation of photoionization mass spectra recorded during SOA formation experiments in smog chambers or mass spectrometric (MS) measurements conducted in the field.

\section{Experimental Details}

Mass spectra and photoion yield curves of three AVOCs and five associated atmospheric degradation products were measured between 7 and $15 \mathrm{eV}$ using monochromatic synchrotron radiation obtained from the electron storage ring BESSY II (Berlin, Germany). The general experimental setup and procedures have been reported elsewhere ${ }^{21}$ and only a brief summary is given here: We used a $3 \mathrm{~m}$ normal incidence monochromator (NIM) connected to a dipole beamline. The monochromator is equipped with a 600 lines/mm grating (Al coated and $\mathrm{MgF}_{2}$ as protection layer). The nominal (reciprocal) dispersion is 5.55 $\AA / \mathrm{mm}$ slit width. The effective slit width is the square root of the sum of squares of the entrance and exit slit widths (in our case, 50 and $250 \mu \mathrm{m}$, respectively, yielding $255 \mu \mathrm{m}$ ). Thus, the bandwidth of the incident monochromatic radiation is $1.4 \AA$ in all experiments (approximately $12 \mathrm{meV}$ at $10 \mathrm{eV}$ ). The experimental step width in a typical photoion yield curve is 10 $\mathrm{meV}$. Completing experiments were performed at the U125/2 undulator beamline at BESSY II which is spectrally more pure and thus better adapted to measurements without cutoff filters. This beamline is equipped with a $10 \mathrm{~m}$ NIM.

Monochromatic VUV light was focused into the ionization region of a quadrupole mass spectrometer (QMS, Leybold
Q200) where the liquid and solid chemical compounds were introduced by a needle valve yielding typical pressures of about $8 \times 10^{-6}$ mbar in the ionization region. Most experiments were carried out using $\mathrm{MgF}_{2}$ or LiF filters (100\% cutoff at 10.8 and $11.8 \mathrm{eV}$, respectively) in order to suppress high-energy stray light and second-order radiation. The Leybold QMS uses a channeltron for ion detection. Ionization and appearance energies were determined with the aid of semilogarithmic plots of the photoion yield curves (see details in section 4.1).

Chemical compounds were commercial products of the highest available purity and were used without further treatment. For measurements on phthalic acid, the ionization region had to be heated to temperatures of about $120-140{ }^{\circ} \mathrm{C}$. We note that this compound shows some thermal degradation after a few minutes at these temperatures, as could be easily observed in the mass spectrum (formation of benzoic acid by loss of $\mathrm{CO}_{2}$ ). Nevertheless, sufficient quantities of nondegraded phthalic acid remained in the spectrometer to permit the measurements. All other compounds had sufficient vapor pressures to allow for measurements at ambient temperature.

\section{Computational Methods}

3.1. Ionization Energies. Adiabatic ionization energies were calculated for all compounds studied experimentally (see Figure 1), and additionally for phthalic anhydride. The purpose of the calculations was twofold: First, the convergence of the computational methods and orbital basis sets was studied, in order to use them in a predictive way, in this work as well as in future work dealing with similar molecular systems. Second, the calculations were compared to the experimental measurements in order to further assess their interpretation.

All calculations were performed with the Gaussian 03 program. ${ }^{22}$ The ionization energies were defined as the energy difference between the cationic and neutral molecules. Adiabatic ionization energies were obtained by relaxing the geometry of the cation. The importance of the inclusion of a zero point energy (ZPE) correction is discussed below.

The following methods were tested for neutral and cationic species: density functional theory (DFT, B3LYP functional ${ }^{23,24}$ ), Møller-Plesset second-order perturbation theory (MP2), ${ }^{25}$ as well as third (MP3) ${ }^{26,27}$ and fourth (MP4) orders, ${ }^{28}$ and coupled clusters with single and double excitations (CCSD) ${ }^{29-32}$ and including perturbative triples $(\operatorname{CCSD}(\mathrm{T})) .{ }^{33}$ For the cations, unrestricted formalisms were used within perturbation theory (UMP2, UMP3, UMP4) and coupled clusters (UCCSD, UCCS$\mathrm{D}(\mathrm{T})$ ). An a posteriori spin contamination correction ${ }^{34}$ (PMP2, PMP3) was also applied in conjunction with the UMP2 and UMP3 methods. Alternatively, for considering second-order perturbations, the restricted open-shell formalism (ROMP2) was investigated as well.

The following basis sets were employed with increasing order of size: (1) 6-31G(d,p), ${ }^{35}$ (2) 6-311++G**,36,37 and (3) ccpVTZ. ${ }^{38}$

For a given basis set, the geometries were optimized with the B3LYP density functional. This method, which is less time consuming than post-Hartree-Fock methods, was also used to calculate the ZPE correction. Using these geometries, the energies were calculated at the above-mentioned higher levels and the results were corrected with the B3LYP ZPE. The separation of the geometry optimization and the energy calculation, treated each by two different methods, has been used with success in the past. ${ }^{39-42}$

3.2. Heats of Formation. The G $2 M P 2^{43}$ and $G 3 B 3^{44}$ methods and related approaches have been designed for 
computing thermochemical properties, such as heats of formation from atomization energies. However, direct application of these methods indicates a tendency for accumulation of errors ${ }^{45}$ which can be high for large molecules as those studied here. Alternatively, to increase accuracy, it was proposed to derive heats of formations from isodesmic reactions (IDRs), and a unique set of such reactions was proposed by means of "bond separation reactions". ${ }^{46}$ Later, G2 and DFT were used within this scheme, in conjunction with accurate experimental data for the fragments of the molecule considered. As a result, a mean absolute deviation of 2-6 $\mathrm{kJ} \mathrm{mol}^{-1}$ from reference experiments could be obtained from a set of 40 molecules composed of up to six non-hydrogen atoms among $\mathrm{H}, \mathrm{C}, \mathrm{O}$, and N. ${ }^{47}$

In the present paper, the molecules under study contain up to 10 non-hydrogen atoms. The following four methods have been used to calculate their enthalpies through isodesmic reactions: $\operatorname{CCSD}(\mathrm{T}) / 6-311++\mathrm{G}^{* *}$ single point with $\mathrm{B} 3 \mathrm{LYP} /$ $6-311++\mathrm{G}^{* *}$ geometry and vibrational corrections, B3LYP/ 6-311++G**, G2MP2, and G3B3. The isodesmic reactions that have been considered are the following (eqs IDR1-IDR9):

$$
\mathrm{C}_{9} \mathrm{H}_{10} \text { (2-methylstyrene) }+9 \mathrm{CH}_{4} \rightarrow 5 \mathrm{C}_{2} \mathrm{H}_{6}+4 \mathrm{C}_{2} \mathrm{H}_{4}
$$

$$
\left.\mathrm{C}_{8} \mathrm{H}_{10} \text { (o-xylene }\right)+8 \mathrm{CH}_{4} \rightarrow 5 \mathrm{C}_{2} \mathrm{H}_{6}+3 \mathrm{C}_{2} \mathrm{H}_{4}
$$

$$
\mathrm{C}_{9} \mathrm{H}_{8} \text { (indene) }+11 \mathrm{CH}_{4} \rightarrow 6 \mathrm{C}_{2} \mathrm{H}_{6}+4 \mathrm{C}_{2} \mathrm{H}_{4}
$$

$$
\mathrm{C}_{8} \mathrm{H}_{8} \text { (o-tolualdehyde) }+9 \mathrm{CH}_{4} \rightarrow 5 \mathrm{C}_{2} \mathrm{H}_{6}+3 \mathrm{C}_{2} \mathrm{H}_{4}+\mathrm{CH}_{2} \mathrm{O}
$$

$$
\begin{array}{r}
\mathrm{C}_{8} \mathrm{H}_{6} \mathrm{O}_{2} \text { (phthaldialdehyde) }+10 \mathrm{CH}_{4} \rightarrow 5 \mathrm{C}_{2} \mathrm{H}_{6}+3 \mathrm{C}_{2} \mathrm{H}_{4}+ \\
2 \mathrm{CH}_{2} \mathrm{O} \text { (IDR5) } \\
\mathrm{C}_{7} \mathrm{H}_{8} \mathrm{O} \text { (2-methylphenol) }+8 \mathrm{CH}_{4} \rightarrow 4 \mathrm{C}_{2} \mathrm{H}_{6}+3 \mathrm{C}_{2} \mathrm{H}_{4}+ \\
\mathrm{CH}_{3} \mathrm{OH} \text { (IDR6) }
\end{array}
$$

$\mathrm{C}_{8} \mathrm{H}_{8}$ (o-toluic acid) $+9 \mathrm{CH}_{4} \rightarrow 5 \mathrm{C}_{2} \mathrm{H}_{6}+3 \mathrm{C}_{2} \mathrm{H}_{4}+\mathrm{HCOOH}$

(IDR7)

$$
\mathrm{C}_{8} \mathrm{H}_{6} \mathrm{O}_{4} \text { (phthalic acid) }+10 \mathrm{CH}_{4} \rightarrow 5 \mathrm{C}_{2} \mathrm{H}_{6}+3 \mathrm{C}_{2} \mathrm{H}_{4}+
$$

$$
\begin{aligned}
& \mathrm{C}_{8} \mathrm{H}_{4} \mathrm{O}_{3} \text { (phthalic anhydride) }+10 \mathrm{CH}_{4}+\mathrm{H}_{2} \mathrm{O} \rightarrow 5 \mathrm{C}_{2} \mathrm{H}_{6}+ \\
& 3 \mathrm{C}_{2} \mathrm{H}_{4}+2 \mathrm{HCOOH} \text { (IDR9) }
\end{aligned}
$$

In these IDRs, the heats of formation of methane and all other reaction products were taken from ref 47 .

\section{Results and Discussion}

In section 4.1, a preliminary discussion is given about the experimental threshold determination and the thermochemical interpretation of IEs and AEs, including also the theoretical work performed on the calculations of heats of formation. In section 4.2, we will discuss the ionization and fragmentation behavior of each compound. In section 4.3, the calculations of the IEs are discussed and compared to the experimental ones.

4.1. Threshold Determination and Thermochemical Interpretation of IEs and AEs. 4.1.1. IE and AE Threshold Determination. Photoion yield curves for parent and selected fragment ions are shown in Figures $2-9$ on a linear scale. All

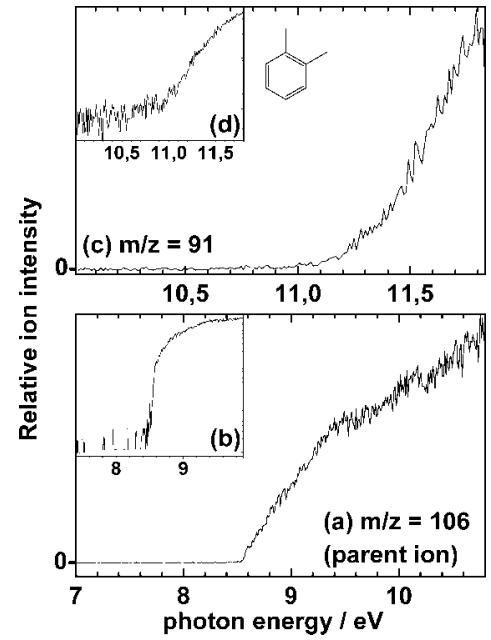

Figure 2. Photoion yield curves of $o$-xylene. (a) $\mathrm{m} / \mathrm{z}=106$ (parent ion, measured with $\mathrm{MgF}_{2}$ filter, linear scale). (b) Same measurement as for (a), log scale. (c) $\mathrm{m} / \mathrm{z}=91$ (measured with LiF filter, linear scale). (d) Same measurement as for (c), log scale.

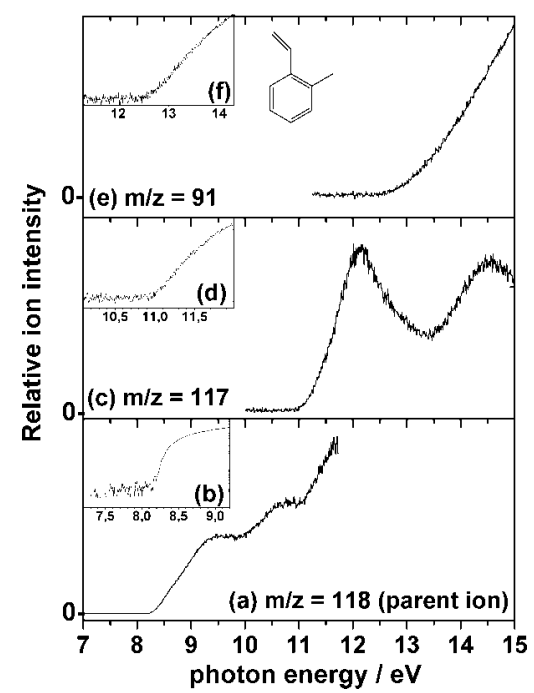

Figure 3. Photoion yield curves of 2-methylstyrene. (a) $\mathrm{m} / \mathrm{z}=118$ (parent ion, measured with $\mathrm{LiF}$ filter, linear scale). (b) Same measurement as for (a), $\log$ scale. (c) $m / z=117$ (no filter, linear scale). (d) Same measurement as for (c), log scale. (e) $\mathrm{m} / \mathrm{z}=91$ (no filter, linear scale). (f) Same measurement as for (e), log scale.

curves shown are unsmoothed, corrected for grating transmission and the decay of BESSY's storage ring current. In the linear representation, the shape of the ion yield curves is not distorted as it is the case in the semilogarithmic representation. However, we use the semilog plots for the determination of the thresholds of ion formation (IEs and AEs). They are shown as insets in each figure. In the semilog representation, a much better distinction of the noise from a real ion signal is possible and thus the threshold determination is significantly facilitated by using the linear rise of the ion yield above the threshold. This implies that autoionization is of negligible importance, which is valid for large molecular systems. The IEs and AEs are tabulated in Table 1.

The experimental error limit is estimated from the semilog plots and is found to be on the order of $0.02-0.05 \mathrm{eV}$, depending on the quality of the ion yield curve (signal-tonoise ratio) and thus finally on the ion signal strength and its rise in the threshold regime. For parent ions, we consider that the ion signal onset determined from PIMS ion yield curves (ours and those cited in the discussion) corresponds 
TABLE 1: Percentage of Relative Ion Yield of Observed Parent and Fragment Ions from QMS Measurements at 15 eV Photon Energy (PI), Observed Ionization and Appearance Energies (IEs and AEs), and Deduced Apparent Heats of Formation ( $\Delta_{\mathrm{f}} H^{\text {app }}$ ) of Assigned Ions ${ }^{a}$

\begin{tabular}{|c|c|c|c|c|c|c|c|}
\hline compound & $\mathrm{m} / \mathrm{z}$ & $\begin{array}{l}\text { PI } 15 \mathrm{eV} \\
\text { rel intensity } \\
\text { (this work) }\end{array}$ & $\begin{array}{c}\text { EI } 70 \mathrm{eV} \\
\text { rel intensity } \\
(\mathrm{NIST} \text { database })^{b}\end{array}$ & ion assignment & $\begin{array}{l}\text { IEs/AEs/eV } \\
\text { (this work) }\end{array}$ & $\begin{array}{c}\Delta_{\mathrm{f}} H^{\mathrm{app} /} \\
\mathrm{kJ} \mathrm{mol}^{-1}\end{array}$ & neutral loss ${ }^{g}$ \\
\hline \multirow{4}{*}{$\begin{array}{l}\text { o-Xylene } \\
\text { (MW: } 106.17 \mathrm{amu})\end{array}$} & 106 & 15 & 63 & $\mathrm{C}_{8} \mathrm{H}_{10}{ }^{+}$ & $8.47 \pm \mathbf{0 . 0 3}$ & $836.2 \pm 4$ & - \\
\hline & 92 & 7 & 8 & ${ }^{13} \mathrm{CC}_{6} \mathrm{H}_{7}{ }^{+}$ & $\sim 11$ & - & $\mathrm{CH}_{3}$ \\
\hline & 91 & 100 & 100 & $\mathrm{C}_{7} \mathrm{H}_{7}^{+}$ & $10.89 \pm 0.05$ & $924.13 \pm 7$ & $\mathrm{CH}_{3}$ \\
\hline & $77,65,63,51,39$ & - & $\mathrm{w}$ & & & & \\
\hline & 116 & 12 & 16 & $\mathrm{C}_{9} \mathrm{H}_{8}{ }^{+}$ & $<13$ & - & $\mathrm{H}_{2}$ \\
\hline & 115 & 14 & 43 & $\mathrm{C}_{9} \mathrm{H}_{7}{ }^{+}$ & $<13$ & - & $H+H_{2}$ \\
\hline & 105 & 4 & 1 & $\mathrm{C}_{8} \mathrm{H}_{9}{ }^{+}$ & $<11$ & - & $\mathrm{CH}$ \\
\hline & 103 & 10 & 10 & $\mathrm{C}_{8} \mathrm{H}_{7}^{+}$ & $<11$ & - & $\mathrm{CH}_{3}$ \\
\hline & 91 & 20 & 33 & $\mathrm{C}_{7} \mathrm{H}_{7}^{+}$ & $12.56 \pm 0.1$ & $1031.3 \pm 15$ & $\mathrm{C}_{2} \mathrm{H}_{3}$ \\
\hline & 78 & 9 & 10 & & & & \\
\hline \multirow{5}{*}{$\begin{array}{l}\boldsymbol{o} \text {-Tolualdehyde } \\
\text { (MW: } 120.15 \mathrm{amu})\end{array}$} & 119 & 48 & 95 & $\mathrm{C}_{8} \mathrm{H}_{7} \mathrm{O}^{+}$ & $11<\mathrm{AE}<12$ & - & $\mathrm{H}$ \\
\hline & 92 & 20 & 10 & $\begin{array}{c}{ }^{13} \mathrm{CC}_{6} \mathrm{H}_{7}^{+} \text {and } \\
\mathrm{C}_{6} \mathrm{H}_{4} \mathrm{O}^{+}\end{array}$ & - & - & $\mathrm{CHO}$ \\
\hline & 91 & 100 & 100 & & $8.78+0.03$ & & $\mathrm{HCO}+\mathrm{C}_{2} \mathrm{H}_{4}$ \\
\hline & 65 & - & $\begin{array}{l}100 \\
27\end{array}$ & $\begin{array}{l}\mathrm{C}_{7} \mathrm{H}_{7} \\
\mathrm{C}_{5} \mathrm{H}_{5}^{+}\end{array}$ & $\begin{array}{l}8.18 \pm 0.03 \\
15.7 \pm 0.1\end{array}$ & $\begin{array}{l}145.4 \pm 8 \\
1186.4 \pm 15\end{array}$ & $\mathrm{HCO}+\mathrm{C}_{2} \mathrm{H}_{4}$ \\
\hline & $63,51,39$ & - & $\mathrm{m}$ & & & & \\
\hline \multirow{5}{*}{$\begin{array}{l}\text { 2-Methylphenol } \\
\text { (MW: } 108.14 \mathrm{amu})\end{array}$} & 108 & 39 & 100 & $\mathrm{C}_{7} \mathrm{H}_{8} \mathrm{O}^{+}$ & $8.16 \pm 0.02$ & $663.3 \pm 2$ & - \\
\hline & 107 & 70 & 68 & $\mathrm{C}_{7} \mathrm{H}_{7} \mathrm{O}^{+}$ & $11.33 \pm 0.1$ & $751.2 \pm 10$ & $\mathrm{H}$ \\
\hline & 91 & 13 & 6 & $\mathrm{C}_{7} \mathrm{H}_{7}^{+}$ & $11.26 \pm 0.1^{f}$ & $923.4 \pm 10$ & $\mathrm{OH}$ \\
\hline & 90 & 45 & 21 & $\mathrm{C}_{7} \mathrm{H}_{6}{ }^{+}$ & $11.57 \pm 0.1$ & $1234.2 \pm 10$ & $\mathrm{H}_{2} \mathrm{O}$ \\
\hline & 89 & 10 & 8 & $\mathrm{C}_{7} \mathrm{H}_{5}{ }^{+}$ & - & - & $\mathrm{OH}+2 \mathrm{H}$ \\
\hline & 89 & & 25 & $\mathrm{C}_{7} \mathrm{H}_{5}^{+}$ & $>11.8$ & - & $\mathrm{CH}_{3} \mathrm{O}_{2}$ \\
\hline & $77,65,63,51,39$ & & $\mathrm{~m}$ & & & & \\
\hline \multirow{10}{*}{$\begin{array}{l}\text { Phthaldialdehyde } \\
\text { (MW: } 134.13 \mathrm{amu})\end{array}$} & 134 & 16 & 35 & $\mathrm{C}_{8} \mathrm{H}_{6} \mathrm{O}_{2}^{+}$ & $9.21 \pm \mathbf{0 . 0 3}$ & $759.3 \pm 8$ & \\
\hline & 107 & 6 & 2 & $\mathrm{C}_{6} \mathrm{H}_{3} \mathrm{O}_{2}^{+}$ & - & - & $\mathrm{C}_{2} \mathrm{H}_{3}$ \\
\hline & 106 & 18 & 37 & $\mathrm{C}_{7} \mathrm{H}_{6} \mathrm{O}^{+}$ & $9.95 \pm 0.1$ & $941.2 \pm 15$ & $\mathrm{CO}$ \\
\hline & 105 & 100 & 100 & $\mathrm{C}_{7} \mathrm{H}_{5} \mathrm{O}^{+}$ & $10.6 \pm 0.2$ & $849.9 \pm 25$ & $\mathrm{HCO}$ \\
\hline & 79 & 8 & 1 & $?$ & - & - & \\
\hline & 78 & 35 & 16 & $\mathrm{C}_{6} \mathrm{H}_{6}^{+}$ & - & - & $2 \mathrm{CO}$ \\
\hline & 77 & 77 & 76 & $\mathrm{C}_{6} \mathrm{H}_{5}{ }^{+}$ & - & - & $\mathrm{HCO}+\mathrm{CO}$ \\
\hline & 76 & 7 & 8 & $\mathrm{C}_{6} \mathrm{H}_{4}^{+}$ & - & - & $2 \mathrm{HCO}$ \\
\hline & 51 & 6 & 38 & $\mathrm{C}_{4} \mathrm{H}_{3}{ }^{+}$ & - & - & \\
\hline & 50,39 & - & $\mathrm{w}$ & & & & \\
\hline \multirow{5}{*}{$\begin{array}{l}\text { Phthalic Acid } \\
\text { (MW: } 166.13 \mathrm{amu} \text { ) }\end{array}$} & 166 & 30 & $<0.1$ & $\mathrm{C}_{8} \mathrm{H}_{6} \mathrm{O}_{4}^{+}$ & $9.42 \pm 0.03$ & $257.6 \pm 4$ & \\
\hline & 148 & 40 & 38 & $\mathrm{C}_{8} \mathrm{H}_{4} \mathrm{O}_{3}{ }^{+}$ & $10.1 \pm 0.1$ & - & $\mathrm{H}_{2} \mathrm{O}^{e}$ \\
\hline & 104 & 100 & 100 & $\mathrm{C}_{7} \mathrm{H}_{4} \mathrm{O}^{+}$ & $<11.8$ & - & $\mathrm{H}_{2} \mathrm{O}+\mathrm{CO}_{2}$ \\
\hline & 76 & 43 & 86 & $\mathrm{C}_{6} \mathrm{H}_{4}^{+}$ & - & - & $\mathrm{H}_{2} \mathrm{O}+\mathrm{CO}_{2}+\mathrm{CO}$ \\
\hline & $74,50,38$ & - & $\mathrm{m}$ & & & & \\
\hline
\end{tabular}

${ }^{a} \mathrm{IE}$ and $\mathrm{AE}$ data from the literature are given in italics; $\mathrm{w}=$ weak intensity, $\mathrm{m}=$ medium intensity. ${ }^{b}$ Reference $55 .{ }^{c}$ Reference 60. ${ }^{d}$ References 63 and $64 .{ }^{e}$ See discussion in the text. ${ }^{f}$ Reference $70 .{ }^{g}$ In italics: plausible assumption.

to the adiabatic ionization energies, and not to the vertical, if the Franck-Condon factors are favorable for this situation. EIMS ion yield curves are not always displayed in the literature, but IEs measured by this method also correspond, in principle, to the adiabatic IEs. PES ionization energies found in the literature can be adiabatic or vertical, depending on the evaluation of the authors. This has been taken into account when they are compared to the present PIMS values.

4.1.2. Thermochemical Interpretation of Measured IEs and AEs. The thermochemistry of a particular fragmentation channel (eq 1) is described by eq 2. We emphasize that our IE and AE values are considered to be upper limit values, since we do not 
TABLE 2: Gas Phase Heats of Formation of Parent Molecules $\left(\Delta_{\mathrm{f}} \mathrm{H}\right)$, in kJ mol $^{-1}$ a

\begin{tabular}{|c|c|c|c|c|c|c|c|c|c|c|}
\hline \multirow[b]{2}{*}{ species } & \multirow{2}{*}{$\begin{array}{c}\Delta_{\mathrm{f}} H, \text { exptl } \\
\text { (gas phase } \\
\text { literature value) }\end{array}$} & \multirow[b]{2}{*}{ ref } & \multicolumn{8}{|c|}{$\Delta_{\mathrm{f}} H$ (calcd, this work) } \\
\hline & & & $\Delta_{\mathrm{f}} H$ & $\Delta_{\mathrm{r}} H(\mathrm{IDR})$ & $\Delta_{\mathrm{f}} H$ & $\Delta_{\mathrm{r}} H(\mathrm{IDR})$ & $\Delta_{\mathrm{f}} H$ & $\Delta_{\mathrm{r}} H(\mathrm{IDR})$ & $\Delta_{\mathrm{f}} H$ & $\Delta_{\mathrm{r}} H(\mathrm{IDR})$ \\
\hline$o$-xylene & $19 \pm 1.1$ & 59 & 42.94 & 293.69 & 33.32 & 303.32 & 21.12 & 315.52 & 21.88 & 314.76 \\
\hline 2-methylstyrene & 118.41 & 76 & 145.49 & 318.57 & 136.93 & 327.13 & 122.73 & 341.33 & 123.4 & 340.66 \\
\hline indene & $163 \pm 1$ & 51 & 192.21 & 337.66 & 173.88 & 355.98 & 165.5 & 364.36 & 165.49 & 364.37 \\
\hline phthalic acid & $-651.32 \pm 1$ & $b, c, d$ & -623.67 & 352.5 & -626.11 & 354.94 & -647.64 & 376.47 & -648.83 & 377.6 \\
\hline phthalic anhydride & $-372.37 \pm 1$ & $b, c$ & -342.69 & 313.48 & -360.26 & 331.04 & -374.41 & 345.19 & -377.84 & 348.63 \\
\hline phthaldialdehyde & unknown & & -99.064 & 368.22 & -127.19 & 396.35 & -127.38 & 396.54 & -129.36 & 398.52 \\
\hline$O$-toluic Acid & $-320.6 \pm 1.5$ & 77 & -290.32 & 323.06 & -302.05 & 334.79 & -316.43 & 349.17 & -316.54 & 349.28 \\
\hline $\mathrm{H}$ & $217.998 \pm 0.006$ & 78 & & & & & & & & \\
\hline $\mathrm{OH}$ & 38.99 & $79(1977)^{e}$ & & & & & & & & \\
\hline $\mathrm{H}_{2} \mathrm{O}$ & $-241.826 \pm 0.040$ & 78 & & & & & & & & \\
\hline $\mathrm{CO}$ & $-110.53 \pm 0.17$ & 78 & & & & & & & & \\
\hline $\mathrm{HCHO}$ & -115.9 & $79(1961)^{e}$ & & & & & & & & \\
\hline
\end{tabular}

${ }^{a}$ Exptl: literature values; calcd: this work. We also list experimental $\Delta_{\mathrm{f}} H$ values of the neutral fragments, which are used in the discussion (section 4.2). For the sake of completeness, the heats of IDR reactions are also given (in italics; difference between $\Delta_{\mathrm{f}} H$ values of products and reactants; cf. section 3.2). The $\Delta_{\mathrm{f}} H$ for a given molecule contains a thermal correction to the total electronic energy; both quantities are provided by the Gaussian 03 software. ${ }^{b}$ Reference 55. ${ }^{c}$ Sum of heat of formation of the solid compound and its heat of sublimation. ${ }^{d}$ Heat of sublimation from ref $81 .{ }^{e}$ Year of last data revision.

make use of coincidence techniques with threshold photoelectrons (TPEPICO). For heats of formation of fragment cations $\mathrm{m}_{1}{ }^{+}$, in particular, we therefore use systematically the superscript "app" (for apparent, cf. eq 2) since AEs are subject to additional shifts (see below).

$$
\begin{gathered}
\mathrm{M}+h v \rightarrow\left(\mathrm{M}^{+}+\mathrm{e}^{-}\right) \rightarrow \mathrm{m}_{1}^{+}+n \mathrm{~m}_{i}+\mathrm{e}^{-} \\
\Delta_{\mathrm{f}} H^{\mathrm{app}}\left(\mathrm{m}_{1}^{+}\right)=\mathrm{AE}\left(\mathrm{m}_{1}^{+}\right)+\Delta_{\mathrm{f}} H(\mathrm{M})-\sum\left[\Delta_{\mathrm{f}} H\left(\mathrm{~m}_{i}\right)\right]
\end{gathered}
$$

In eqs 1 and $2, \mathrm{~m}_{i}$ are the neutral products formed in the fragmentation reaction, eq 1 . In principle, the thermal energy content of the parent neutral $\left(E_{\mathrm{th}}\right)$ has to be subtracted from the measured IEs and AEs. On the contrary, activation barriers of photodissociation reactions lead to the measurement of too-high AEs. A fragment AE can in addition be subject to a substantial kinetic shift, $\Delta E_{\text {kin }}$, again leading to a too-high $\mathrm{AE}$ value (also Franck-Condon factors may be poor). The magnitude of $\Delta E_{\text {kin }}$ is difficult to know without supplementary experiments and/or dynamic calculations. ${ }^{48}$ However, we indicate that $\Delta E_{\text {kin }}$ and $E_{\mathrm{th}}$ can, at least in part, be canceled out since they shift the $\mathrm{AE}$ towards opposite directions. This can yield, in fine, fairly accurate values as has been noted in ref 49. Earlier work performed on PAHs also indicates that $\Delta E_{\text {kin }}$ (with the rate constant $k$ going from $10^{2}$ to $10^{4} \mathrm{~s}^{-1}$ ) and $E_{\text {th }}$ are of comparable extent for molecules of our size, within a factor of about $2 .{ }^{50}$ That is why we did not attempt any AE correction, but just use measured AEs as read from the yield curves. We finally note that all AEs determined in this study are nevertheless lower than or equal to existing literature data. Dynamic calculations will be performed in the future in order to correctly account for kinetic effects.

The apparent heats of formation $\Delta_{\mathrm{f}} H^{\text {app }}$ of fragment cations $\mathrm{m}_{1}{ }^{+}$are listed in Table 1 . They are determined adopting the ion convention (also called the "stationary electron convention").
This convention is widely used including the compilation of Lias et al. ${ }^{51}$ The $\Delta_{\mathrm{f}} H$ values of involved neutral species were taken from the literature (cf. Table 2). In two cases, for $o$-tolualdehyde and phthaldialdehyde, we used our calculated $\Delta_{\mathrm{f}} H$ values (cf. section 4.1.3) since experimental data are unknown to our knowledge. An ion $\mathrm{m}_{1}^{+}$can be formed by different possible fragmentation pathways where several neutral fragments $\mathrm{m}_{i}$ might have to be considered (including their isomers). If the heat of formation of $\mathrm{m}_{1}{ }^{+}$is known, one can compare it to the experimentally determined $\Delta_{\mathrm{f}} H^{\text {app }}$, which often permits an assignment of a particular fragmentation channel or conclusions on the chemical structure of the ion that is formed.

4.1.3. Theoretical Calculation of Heats of Formation of Parent Neutrals. The results obtained for the calculation of heats of formation are shown in Table 2. From comparison of the calculated results with the known experimental data for $o$-xylene, 2-methylstyrene, indene, 2-methylphenol, phthalic acid, phthalic anhydride, and $o$-toluic acid, we found the best agreement with the G2MP2 and G3B3 methods; the results of the two latter methods were in fact very close. This is not surprising since the " $G$ " methods have been especially developed for accurate thermochemical calculations and were already found to work satisfactorily well for medium-size hydrocarbons. ${ }^{45,52,53}$ It has also been shown that further accuracy can only be achieved at significantly higher calculation times by extrapolation of the method and the basis set. ${ }^{54}$ However, these methods are presently not affordable for the molecules considered in this work, because of a too-high calculation time. In the discussion of section 4.2 we assume an error limit of $5 \mathrm{~kJ} \mathrm{~mol}^{-1}$ corresponding to the observed mean deviation from experimental data known from the literature (cf. Table 2).

4.2. Ionization and Disscociative Ionization of Aerosol Constituents and Precursors. Mass spectra of all compounds have been recorded at several fixed photon energies $(12,15$, 
18, and $20 \mathrm{eV}$ ). In Table 1 we show relative ion intensities at the photon energy $E=15 \mathrm{eV}(\lambda=82.66 \mathrm{~nm})$, in comparison with $70 \mathrm{eV}$ electron impact mass spectra from the NIST database. ${ }^{55}$ The ${ }^{13} \mathrm{C}$ isotopomers of the parent cations are excluded in Table 1. We consider it useful to compare the fragmentation patterns of our PI mass spectra to the widely used $70 \mathrm{eV}$ EI mass spectra of the NIST database, even though artifacts, such as different ion transmission efficiencies of the mass analyzers, might obstruct a meaningful comparison. The $15 \mathrm{eV}$ PI and $70 \mathrm{eV}$ EI mass spectra are of essentially the same fragments; however, their relative intensities are different (cf. Table 1). These differences are discussed in the text where useful.

4.2.1. o-Xylene, $\boldsymbol{C}_{8} \boldsymbol{H}_{10}$. The mass spectrum of this compound shows only four ions at $E=15 \mathrm{eV}$, at $\mathrm{m} / \mathrm{z}=106,105,92$, and 91. The $m / z=91$ ion is the most intense mass peak, in both our $15 \mathrm{eV}$ PIMS and in the $70 \mathrm{eV}$ EIMS. The higher parent ion intensity $(\mathrm{m} / \mathrm{z}=106)$ in the EIMS might be due to different ion transmission characteristics of the mass analyzers. Another reason could be a lower partial cross section for dissociative ionization in the EI mode, due to inefficient inelastic scattering of the electrons.

Our measured value for the ionization energy of $o$-xylene (using a $\mathrm{MgF}_{2}$ filter), is $8.47 \pm 0.03 \mathrm{eV}$ (cf. Figure 2a,b). An earlier PIMS measurement by Watanabe gave IE $=8.56 \pm 0.01$ $\mathrm{eV} .{ }^{56}$ Later, other groups used EI measurements (IE $=8.85 \pm$ $\left.0.05 \mathrm{eV}^{57}\right)$ and PES $\left(\mathrm{IE}_{\mathrm{vert}}=8.45 \pm 0.02 \mathrm{eV}^{58}\right)$. The PES value from ref 58 is the vertical IE, but the adiabatic value is approximately the same, since the rise of the first PES band is very sharp, as can be seen from the PE spectrum. This is in agreement with our theoretical results on the geometry change during ionization being insignificant for this molecule (see section 4.3). Our IE value is $0.11 \mathrm{eV}$ lower than Watanabe's, probably due to a better detection sensitivity of our instrumental setup. Using the known heat of formation of the neutral $\left(\Delta_{\mathrm{f}} H(o-\right.$ xylene $\left.)=19.0 \pm 1.1 \mathrm{~kJ} \mathrm{~mol}^{-1}\right),{ }^{59}$ we determine the heat of formation of $\mathrm{C}_{8} \mathrm{H}_{10}{ }^{+}$to be $\Delta_{\mathrm{f}} H\left(o\right.$-xylene $\left.{ }^{+}\right)=836.2 \pm 4 \mathrm{~kJ}$ $\mathrm{mol}^{-1}$.

Below $15 \mathrm{eV}$, two fragmentation reactions are dominant:

$$
\begin{aligned}
& \mathrm{C}_{8} \mathrm{H}_{10}{ }^{+}(m / z=106) \rightarrow \mathrm{C}_{8} \mathrm{H}_{9}{ }^{+}(m / z=105)+\mathrm{H} \\
& \mathrm{C}_{8} \mathrm{H}_{10}{ }^{+}(m / z=106) \rightarrow \mathrm{C}_{7} \mathrm{H}_{7}{ }^{+}(m / z=91)+\mathrm{CH}_{3}
\end{aligned}
$$

Fragment ion appearance energy measurements have been made previously for $\mathrm{C}_{8} \mathrm{H}_{9}{ }^{+}(\mathrm{m} / \mathrm{z}=105)$ and $\mathrm{C}_{7} \mathrm{H}_{7}+(\mathrm{m} / \mathrm{z}=91) .57,60$ Concerning the $\mathrm{C}_{8} \mathrm{H}_{9}{ }^{+}$cation, the previous PIMS value was $\mathrm{AE}$ $=11.30 \pm 0.05 \mathrm{eV},{ }^{60}$ yielding $\Delta_{\mathrm{f}} H\left(\mathrm{C}_{8} \mathrm{H}_{9}{ }^{+}\right)=891.3 \pm 15 \mathrm{~kJ}$ $\mathrm{mol}^{-1}$. This is higher than $\Delta_{\mathrm{f}} H$ values found in ref 51 for four different $\mathrm{C}_{8} \mathrm{H}_{9}{ }^{+}$isomers, with the difference ranging from 36 to $60 \mathrm{~kJ} \mathrm{~mol}^{-1}$. This indicates that the AE from ref 60 is probably too high.

We measured an onset energy for the $\mathrm{C}_{7} \mathrm{H}_{7}{ }^{+}$cation $(\mathrm{m} / \mathrm{z}=$ 91) to be $\mathrm{AE}=10.89 \pm 0.05 \mathrm{eV}$ (using the LiF filter, cf. Figure $2 \mathrm{c}, \mathrm{d})$. This agrees well with the value $11.10 \pm 0.05 \mathrm{eV}$ from ref 60 , with the difference being possibly due to a lower detection sensitivity in the older measurements leading to a high $\Delta E_{\text {kin. }}$. We mention also an electron impact value of $11.2 \pm 0.1$ $\mathrm{eV}$ from ref 61 . Using our new $\mathrm{AE}$ and the heat of formation of $\mathrm{CH}_{3}$ from Table 2, we can calculate the apparent heat of formation of $\mathrm{C}_{7} \mathrm{H}_{7}{ }^{+}$formed in the dissociative ionization of $o$-xylene to be $\Delta_{\mathrm{f}} H^{\mathrm{app}}\left(\mathrm{C}_{7} \mathrm{H}_{7}{ }^{+}\right)=924.13 \pm 7 \mathrm{~kJ} \mathrm{~mol}^{-1}$. This is approximately the same value that is found when $\mathrm{C}_{7} \mathrm{H}_{7}{ }^{+}$is formed from dissociative photoionization of other cyclic and bicyclic precursors. ${ }^{21} \mathrm{We}$ thus suggest that the ion has a similar structure which could be either the tropylium ion structure $\left(\Delta_{\mathrm{f}} H\left(\mathrm{Tr}-\mathrm{C}_{7} \mathrm{H}_{7}{ }^{+}\right)=849 \mathrm{~kJ} \mathrm{~mol}{ }^{-1}\right)^{51}$ or the benzylium ion structure $\left(\Delta_{\mathrm{f}} H\left(\mathrm{Bz}_{-} \mathrm{C}_{7} \mathrm{H}_{7}{ }^{+}\right)=899 \mathrm{~kJ} \mathrm{~mol}^{-1}\right)^{51}$. The difference from the $\Delta_{\mathrm{f}} H^{\text {app }}$ value determined in this study is possibly due a remaining kinetic energy shift.

The $m / z=92$ ion is most certainly the ${ }^{13} \mathrm{C}$ isotopomer of the $\mathrm{m} / \mathrm{z}=91$ cation, since its intensity is $8 \%$ of the latter, corresponding almost exactly to the expected value (7.7\%). We also attempted to measure its appearance energy (without $\mathrm{LiF}$ filter), and it is found to be roughly $11 \mathrm{eV}$, which confirms this assumption.

4.2.2. 2-Methylstyrene, $\boldsymbol{C}_{9} \boldsymbol{H}_{10}$. The $15 \mathrm{eV} \mathrm{MS}$ of this compound shows eight different ions, with $\mathrm{m} / \mathrm{z}=118$ (parent ion), 117, 116, 115, 105, 103, 91, and 78 (see Table 1). In the $12 \mathrm{eV}$ mass spectrum (not shown), most of the fragment ions have vanished or have very low intensity, except for $\mathrm{m} / \mathrm{z}=117$ which is still the strongest ion. In the $E=20 \mathrm{eV}$ PIMS, the fragment ions $m / z=77$ (probably the phenyl cation $\mathrm{C}_{6} \mathrm{H}_{5}{ }^{+}$), $65\left(\mathrm{C}_{5} \mathrm{H}_{5}^{+}\right), 53\left(\mathrm{C}_{4} \mathrm{H}_{5}{ }^{+}\right)$, and $39\left(\mathrm{C}_{3} \mathrm{H}_{3}{ }^{+}\right)$also appear. The latter four ions are typical fragments of aromatic monocycles like toluene $^{21}$ and are also observed in the $70 \mathrm{eV}$ EI mass spectrum. ${ }^{55}$

For the parent ion of 2-methylstyrene, $m / z=118$, we measured an ionization energy of IE $=8.17 \pm 0.03 \mathrm{eV}$ (Figure $3 \mathrm{a}, \mathrm{b}$; measured with $\mathrm{LiF}$ filter). Our value is in excellent agreement with the adiabatic IE determined from the PE spectrum $\left(\mathrm{IE}_{\mathrm{ad}}=8.20 \pm 0.02 \mathrm{eV}\right){ }^{58}$ The vertical IE is found to be $\mathrm{IE}_{\mathrm{vert}}=8.50 \mathrm{eV} .{ }^{58}$ This behavior is in accordance with our calculations which indicate a significant geometry change during ionization (see section 4.3 and Figure 10). We calculate $\Delta_{\mathrm{f}} H\left(2\right.$-methylstyrene $\left.{ }^{+}\right)=906.7 \pm 3 \mathrm{~kJ} \mathrm{~mol}^{-1}$.

The appearance energy of the intense $\mathrm{C}_{9} \mathrm{H}_{9}{ }^{+}$ion $(\mathrm{m} / \mathrm{z}=117)$, formed by $\mathrm{H}$-loss reaction, is $\mathrm{AE}=10.98 \pm 0.03 \mathrm{eV}$. Its photoion yield curve shown in Figure $3 \mathrm{c}$, d has been measured without a $\mathrm{LiF}$ filter. Additional measurement with a LiF filter are in full agreement with this value. Using the experimental heat of formation of 2-methylstyrene (cf. Table 2), we can determine its apparent heat of formation to be $\Delta_{\mathrm{f}} H^{\text {app }}\left(\mathrm{C}_{9} \mathrm{H}_{9}{ }^{+}\right)$ $=959.8 \pm 3 \mathrm{~kJ} \mathrm{~mol}^{-1}$. The structure of this ion has been investigated by Köppel et al., ${ }^{62}$ who studied its formation by dissociative EI ionization from different precursors, including $\alpha$-methylstyrene, where the methyl group is attached to the vinyl substituent, and 4-methylstyrene. These authors also estimated heats of formation for different isomeric structures. Our $\Delta_{\mathrm{f}} H^{\mathrm{app}}\left(\mathrm{C}_{9} \mathrm{H}_{9}{ }^{+}\right)$value coincides either with a vinyl-substituted tropylium ion proposed in ref 62 , or with a value determined by proton affinity measurements of 1-ethynyl-4-methylbenzene $\left(951 \mathrm{~kJ} \mathrm{~mol}^{-1}\right) .{ }^{51} \mathrm{New} \Delta_{\mathrm{f}} H$ calculations of this ion are probably necessary to clarify definitely its structure when formed from 2-methylstyrene or similar precursors.

The appearance energy of the $\mathrm{C}_{7} \mathrm{H}_{7}{ }^{+}$cation $(\mathrm{m} / \mathrm{z}=91)$ formed in the dissociative photionization of 2-methylstyrene is determined to be $\mathrm{AE}=12.56 \pm 0.1 \mathrm{eV}$ (Figure 3e,f; reaction 5).

$$
\mathrm{C}_{9} \mathrm{H}_{10}{ }^{+}(m / z=118) \rightarrow \mathrm{C}_{7} \mathrm{H}_{7}{ }^{+}(m / z=91)+\mathrm{C}_{2} \mathrm{H}_{3}
$$

Assuming that the neutral fragment $\mathrm{C}_{2} \mathrm{H}_{3}$ is the vinyl radical and taking its tabulated heat of formation (see Table 2), we can calculate $\Delta_{\mathrm{f}} H^{\mathrm{app}}\left(\mathrm{C}_{7} \mathrm{H}_{7}{ }^{+}\right)=1031.3 \pm 15 \mathrm{~kJ} \mathrm{~mol}^{-1}$. This is a relatively high value compared to that of the tropylium or benzylium ion, indicating that $\mathrm{C}_{7} \mathrm{H}_{7}{ }^{+}$formed in reaction 5 might have an open chain structure (cf. ref 21) or that reaction 5 is related to a large kinetic shift. Additional theoretical work is necessary to clarify this. 


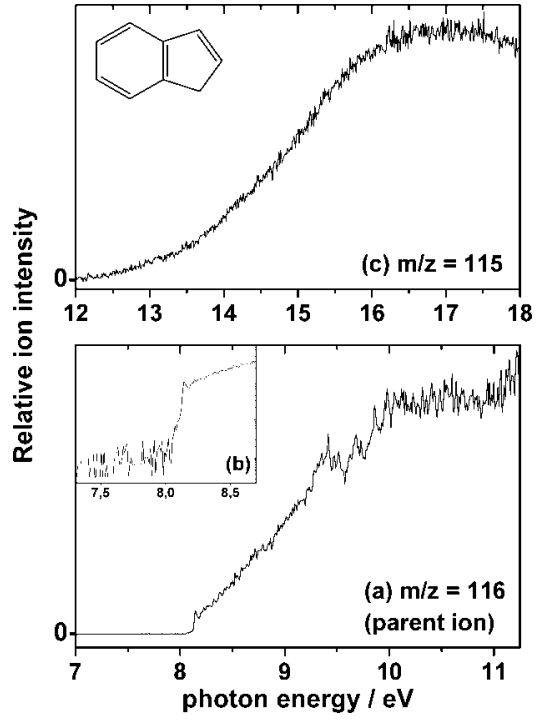

Figure 4. Photoion yield curves of indene. (a) $\mathrm{m} / \mathrm{z}=116$ (parent ion, measured with LiF filter, linear scale). (b) Same measurement as for (a), $\log$ scale. (c) $m / z=115$ (no filter, linear scale).

The appearance of the weak ions $m / z=116,115,105$, and 103 (reactions 6-9) has been observed by recording a series of mass spectra at 10,11,12,13,14, and $15 \mathrm{eV}$ (not shown).

$$
\begin{aligned}
& \left.\mathrm{C}_{9} \mathrm{H}_{10}{ }^{+}{ }^{+} m / z=118\right) \rightarrow \mathrm{C}_{9} \mathrm{H}_{8}{ }^{+}(m / z=116)+2 \mathrm{H} \\
& \mathrm{C}_{9} \mathrm{H}_{10}{ }^{+}{ }^{+}(m / z=118) \rightarrow \mathrm{C}_{9} \mathrm{H}_{7}{ }^{+}(m / z=115)+3 \mathrm{H} \\
& \mathrm{C}_{9} \mathrm{H}_{10}{ }^{+}{ }^{+}(m / z=118) \rightarrow \mathrm{C}_{8} \mathrm{H}_{9}{ }^{+}(m / z=105)+\mathrm{CH} \\
& \mathrm{C}_{9} \mathrm{H}_{10}{ }^{+}(m / z=118) \rightarrow \mathrm{C}_{8} \mathrm{H}_{7}{ }^{+}{ }^{+}(m / z=103)+\mathrm{CH}_{3}
\end{aligned}
$$

Table 1 indicates lower energy limits where these ions form. Their structures remain to be clarified in the future. Schwarz and Bohlmann measured AEs of the $\mathrm{C}_{9} \mathrm{H}_{7}{ }^{+}$ion $(\mathrm{m} / \mathrm{z}=115)$, formed by dissociative EI ionization of different neutral precursors including indene (but not 2-methylstyrene, see also below). ${ }^{63}$ Several structures have been proposed for this ion, but no final conclusion could be drawn as to which $\mathrm{C}_{9} \mathrm{H}_{7}{ }^{+}$ isomer had been formed in their experiments. Earlier work proposed an ethynyl-substituted tropylium ion to be the carrier of mass peak $\mathrm{m} / \mathrm{z}=115 .{ }^{64} \mathrm{The} \mathrm{C}_{8} \mathrm{H}_{9}{ }^{+}$ion $(\mathrm{m} / \mathrm{z}=105)$ could be a methyl-substituted tropylium or benzylium ion.

4.2.3. Indene, $\boldsymbol{C}_{9} \boldsymbol{H}_{8}$. Our $15 \mathrm{eV}$ PI mass spectrum shows only two ions, the parent ion $(\mathrm{m} / \mathrm{z}=116)$ and the intense fragment ion $\mathrm{C}_{9} \mathrm{H}_{7}{ }^{+}$corresponding to the $\mathrm{H}$-loss reaction of this compound. At $20 \mathrm{eV}$ an additional fragment ion, $\mathrm{m} / \mathrm{z}=89$, is observed. The PIMS value for the ionization energy of indene, measured with the $\mathrm{LiF}$ filter, is found to be $\mathrm{IE}=8.05 \pm 0.03$ $\mathrm{eV}$ (cf. Figure 4a,b). This is much lower than the electron impact value, $8.33 \pm 0.01 \mathrm{eV}$, given by Rakita et al. ${ }^{65}$ and $\mathrm{IE}_{\mathrm{vert}}=$ $8.16 \pm 0.015 \mathrm{eV}$ obtained by the most recent PE-spectral measurement. ${ }^{66}$ It can be concluded from the sharp onset of the high resolution PE spectrum that the adiabatic IE is very close to $\mathrm{IE}_{\text {vert }}$, at approximately $8.10 \mathrm{eV} \cdot{ }^{66}$ Using our IE value, we calculate a new heat of formation of this ion, to be $\Delta_{\mathrm{f}} H\left(\right.$ indene $\left.^{+}\right)=939.7 \pm 4 \mathrm{~kJ} \mathrm{~mol}^{-1}$. The indene parent ion yield curve shows some structure, between 9.2 and $10 \mathrm{eV}$. The observed bands probably correspond to Rydberg transitions converging to the third ionization limit, found at $10.29 \mathrm{eV} .{ }^{66}$

The appearance energy of the $\mathrm{C}_{9} \mathrm{H}_{7}{ }^{+}$ion $(\mathrm{m} / \mathrm{z}=115)$, corresponding to the $\mathrm{H}$-loss reaction of the indene cation, could not be determined because of the very smooth onset in the

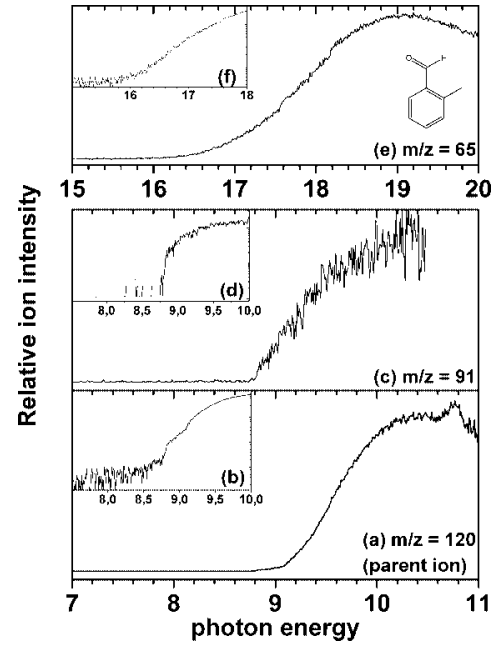

Figure 5. Photoion yield curves of $o$-tolualdehyde. (a) $\mathrm{m} / \mathrm{z}=120$ (parent ion, measured with $\mathrm{MgF}_{2}$ filter, linear scale). (b) Same measurement as for (a), $\log$ scale. (c) $\mathrm{m} / \mathrm{z}=91$ (measured with $\mathrm{MgF}_{2}$ filter, linear scale). (d) Same measurement as for (c), log scale. (e) $\mathrm{m} / \mathrm{z}$ $=65$ (no filter, linear scale). (f) Same measurement as for (e), $\log$ scale.

photoion yield curve of this ion (cf. Figure 4c). However, in a mass spectrum recorded with zero-order light of the grating and applying a $\mathrm{LiF}$ filter $(E<11.8 \mathrm{eV})$, this ion is not visible (meaning $\mathrm{AE}>11.8 \mathrm{eV}$ ). On the contrary, the $\mathrm{AE}$ found from an older EI measurement ${ }^{64}(12.53 \mathrm{eV})$ is probably too high. An ethynyl tropylium ion structure has been proposed for this ion. ${ }^{64}$ Whether an ionized indenyl radical is the carrier of $\mathrm{m} / \mathrm{z}$. $=115$ formed from the indene parent cation cannot be decided without new data on the heat of formation of this species.

4.2.4. o-Tolualdehyde, $\mathrm{C}_{8} \mathrm{H}_{8} \mathrm{O}$. According to smog chamber experiments, $o$-tolualdehyde (or 2-methylbenzaldehyde) is a degradation product of 2-methylstyrene ${ }^{67}$ and also of $o$-xylene. ${ }^{68}$ Its $15 \mathrm{eV}$ PI mass spectrum shows four ions: the parent ion $(\mathrm{m} / \mathrm{z}=120)$; the fragment ion $\mathrm{m} / \mathrm{z}=119$, corresponding to the H-loss reaction; the $m / z=92$ ion; and the $m / z=91$ ion, which is the most intense. The $18 \mathrm{eV}$ PI mass spectrum shows an additional ion, at $m / z=65$. The $70 \mathrm{eV}$ EI mass spectrum from the NIST database shows additional intense ions at $\mathrm{m} / z=63$, 51, and 39 (see Table 1).

Photoion yield curves of $o$-tolualdehyde are shown in Figure 5. Our PIMS ionization energy of this molecule, measured with the $\mathrm{MgF}_{2}$ filter, is found to be IE $=8.75 \pm 0.03 \mathrm{eV}$ (Figure $5 \mathrm{a}, \mathrm{b})$. No literature data were available for its ionization energy. The experimental heat of formation of neutral $o$-tolualdehyde is unknown to our knowledge, so we used our calculated $\Delta_{\mathrm{f}} H$ for the parent ion (G3B3 method, see Table 2) to deduce $\Delta_{\mathrm{f}} H(o-$ tolualdehyde $\left.{ }^{+}\right)=786 \pm 8 \mathrm{~kJ} \mathrm{~mol}^{-1}$. Here, the error limit corresponds to the uncertainty of the calculations (cf. section 4.1.3), which adds to the experimental error limit. We note that the isomer $p$-tolualdehyde has a significantly higher ionization energy $(9.33 \pm 0.05 \mathrm{eV}){ }^{51}$

The appearance energy of the major fragment ion $\mathrm{m} / \mathrm{z}=91$ is determined to be $\mathrm{AE}=8.78 \pm 0.03 \mathrm{eV}$ (Figure 5c,d). At approximately the same energy, the parent ion yield curve shows an inflection and continues to rise less steeply (cf. Figure 5b). Comparing Figure 5a and Figure 5c, the two ion yield curves are shown on different scales. The intensity ratio $I(\mathrm{~m} / \mathrm{z}=91) /$ $I(\mathrm{~m} / \mathrm{z}=120)$ is approximately $2 \%$ between 10 and $11 \mathrm{eV}$. The $m / z=91$ ion is most probably the $\mathrm{C}_{7} \mathrm{H}_{7}{ }^{+}$ion (and not $\mathrm{C}_{6} \mathrm{H}_{3} \mathrm{O}^{+}$), possibly formed by reaction 10 : 


$$
\mathrm{C}_{8} \mathrm{H}_{8} \mathrm{O} \rightarrow \mathrm{C}_{7} \mathrm{H}_{7}^{+}(m / z=91)+\mathrm{HCO}
$$

Using our calculated $\Delta_{\mathrm{f}} H$ for $o$-tolualdehyde, we can determine $\Delta_{\mathrm{f}} H^{\mathrm{app}}\left(\mathrm{C}_{7} \mathrm{H}_{7}{ }^{+}\right)=745.4 \pm 8 \mathrm{~kJ} \mathrm{~mol}^{-1}$ according to reaction 10. This is a lot lower than values of either the tropylium (849 $\left.\mathrm{kJ} \mathrm{mol}^{-1}\right)^{51}$ or the benzylium ion $\left(899 \mathrm{~kJ} \mathrm{~mol}^{-1}\right){ }^{51}$ This is surprising since $\mathrm{Tr}-\mathrm{C}_{7} \mathrm{H}_{7}{ }^{+}$and $\mathrm{Bz}-\mathrm{C}_{7} \mathrm{H}_{7}{ }^{+}$are thought to be the lowest energy structures of $\mathrm{C}_{7} \mathrm{H}_{7}{ }^{+}$. Formation of $\mathrm{COH}$ in reaction 10 is unlikely since calculations performed for this species indicate that its $\Delta_{\mathrm{f}} H$ is much higher than that of HCO. Assuming successive loss of $\mathrm{CO}$ and $\mathrm{H}$ leads to an even lower $\Delta_{\mathrm{f}} H^{\text {app }}$ value for $\mathrm{C}_{7} \mathrm{H}_{7}{ }^{+}$. Another origin for this disagreement could be a false calculation of the $\Delta_{\mathrm{f}} H$ of neutral $o$-tolualdehyde, being too low by about $100 \mathrm{~kJ} \mathrm{~mol}^{-1}$. This is, however, also not very likely since the $\Delta_{\mathrm{f}} H$ calculations for the molecules under study are very coherent and the methods used have been proven in the past to give satisfactory results. A syn isomer has also been considered in the calculations (not shown in Table 2 ), with the oxygen atom pointing towards the methyl group. However, its $\Delta_{\mathrm{f}} H$ is "only" $3 \mathrm{~kJ} \mathrm{~mol}^{-1}$ lower than that of the anti isomer shown in Figure 1. Finally, we considered ion pair formation according to reaction 11:

$$
\mathrm{C}_{8} \mathrm{H}_{8} \mathrm{O} \rightarrow \mathrm{C}_{7} \mathrm{H}_{7}^{+}(m / z=91)+\mathrm{HCO}^{-}
$$

However, the $\Delta_{\mathrm{f}} H^{\mathrm{app}}\left(\mathrm{C}_{7} \mathrm{H}_{7}{ }^{+}\right)$would still be significantly below $\left(\sim 70 \mathrm{~kJ} \mathrm{~mol}^{-1}\right)$ the $\Delta_{\mathrm{f}} \mathrm{H}$ values of $\mathrm{Tr}-\mathrm{C}_{7} \mathrm{H}_{7}{ }^{+}$and $\mathrm{Bz}_{-} \mathrm{C}_{7} \mathrm{H}_{7}+$ since the electron affinity of $\mathrm{HCO}$ is known to be $30.2 \mathrm{~kJ} \mathrm{~mol}^{-1}$. 11 Thus, at present, we cannot give a satisfactory explanation for the very low $\Delta_{\mathrm{f}} H^{\mathrm{app}}\left(\mathrm{C}_{7} \mathrm{H}_{7}{ }^{+}\right)$when $\mathrm{C}_{7} \mathrm{H}_{7}{ }^{+}$is formed from $o$-tolualdehyde. This is an interesting point to be studied in the future.

The intensity of the $\mathrm{m} / \mathrm{z}=92$ ion is at $20 \%$ of the $\mathrm{m} / \mathrm{z}=91$ ion. This is significantly above the expected intensity of a ${ }^{13} \mathrm{C}$ isotopomer of $\mathrm{C}_{7} \mathrm{H}_{7}{ }^{+}$. We conclude that other fragmentation channels could contribute to the observed ion intensity of $\mathrm{m} / \mathrm{z}$ $=92$, such as reaction 12 :

$$
\mathrm{C}_{8} \mathrm{H}_{8} \mathrm{O}^{+}(m / z=120) \rightarrow \mathrm{C}_{6} \mathrm{H}_{4} \mathrm{O}^{+}(m / z=92)+\mathrm{C}_{2} \mathrm{H}_{4}
$$

We also measured the appearance energy of the $\mathrm{m} / \mathrm{z}=65$ ion to be at $15.7 \pm 0.1 \mathrm{eV}$ (Figure 5e,f). This ion $\left(\mathrm{C}_{5} \mathrm{H}_{5}{ }^{+}\right)$is probably formed by $\mathrm{C}_{2} \mathrm{H}_{2}$ loss of the $\mathrm{C}_{7} \mathrm{H}_{7}{ }^{+}$ion as it is the case for toluene and xylene isomers. We deduce $\Delta_{\mathrm{f}} H^{\mathrm{app}}\left(\mathrm{C}_{5} \mathrm{H}_{5}{ }^{+}\right)=$ $1186.4 \pm 15 \mathrm{~kJ} \mathrm{~mol}^{-1}$ assuming $\mathrm{HCO}$ and $\mathrm{C}_{2} \mathrm{H}_{2}$ loss. This is a little higher than values from the literature $(1012-1158 \mathrm{~kJ}$ $\mathrm{mol}^{-1}$, depending on the isomer). ${ }^{21}$

4.2.5. 2-Methylphenol, $\mathrm{C}_{7} \mathrm{H}_{8} \mathrm{O}$. 2-Methylphenol, also wellknown as a disinfectant (" $O$-cresol"), is a major degradation product of 2-methylstyrene in the atmosphere. ${ }^{67}$ Its $15 \mathrm{eV}$ PI mass spectrum shows eight ions (cf. Table 1): $\mathrm{m} / \mathrm{z}=108$ (parent ion), 107, 91, 90, 89, 80, 79, and 77. We measured the ionization energy of this compound to be IE $=8.16 \pm$ $0.02 \mathrm{eV}$ (with LiF filter, cf. Figure 6a,b). This value is in excellent agreement with the EI ionization energy measurement reported by Russel et al. ${ }^{69}(8.14 \mathrm{eV}$, experimental uncertainty is estimated to be $0.1-0.2 \mathrm{eV})$. We mention the much higher EI ionization value published by Selim et al., who measured IE $=8.46 \pm 0.06 \mathrm{eV} .{ }^{70}$ An older PES value obtained by Maier and Turner yielded $\mathrm{IE}_{\mathrm{ad}}=8.24 \pm 0.02$ $\mathrm{eV} .{ }^{71}$ Using the IE from this work, we can deduce the heat of formation of the 2-methylphenol cation to be $\Delta_{\mathrm{f}} H(2-$ methylphenol ${ }^{+}$) $=663.3 \pm 2 \mathrm{~kJ} \mathrm{~mol}^{-1}$.

Our appearance energy measurement for the $\mathrm{C}_{7} \mathrm{H}_{7} \mathrm{O}^{+}$ion $(\mathrm{m} / \mathrm{z}$ $=107$, formed by $\mathrm{H}$-loss reaction) is $\mathrm{AE}=11.33 \pm 0.1 \mathrm{eV}$

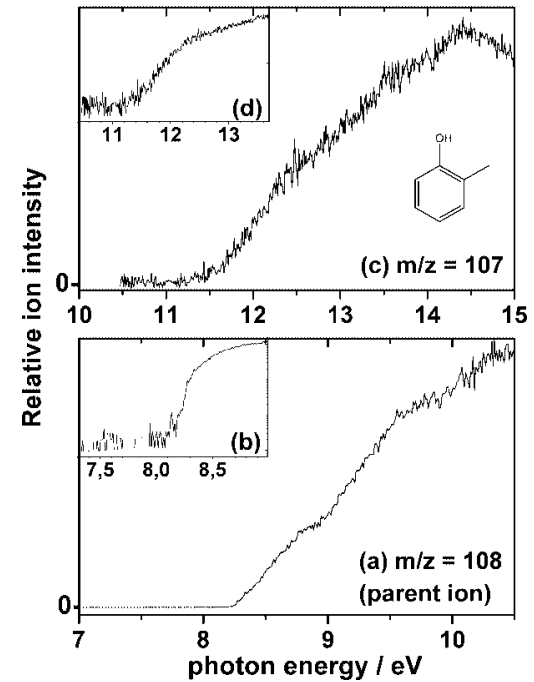

Figure 6. Photoion yield curves of 2-methylphenol. (a) $\mathrm{m} / \mathrm{z}=108$ (parent ion, measured with $\mathrm{MgF}_{2}$ filter, linear scale). (b) Same measurement as for (a), log scale. (c) $\mathrm{m} / \mathrm{z}=107$ (no filter, linear scale). (d) Same measurement as for (c), log scale.

$\left(1093.2 \pm 10 \mathrm{~kJ} \mathrm{~mol}^{-1}\right.$, cf. Figure 6c,d), again in excellent agreement with the work reported in ref $69(1081 \pm 15 \mathrm{~kJ}$ $\mathrm{mol}^{-1}$ ). Using the known heats of formation of 2-methylphenol and $\mathrm{H}$, we deduce an apparent heat formation of $\Delta_{\mathrm{f}} H^{\mathrm{app}}\left(\mathrm{C}_{7} \mathrm{H}_{7} \mathrm{O}^{+}\right)=751.2 \pm 10 \mathrm{~kJ} \mathrm{~mol}^{-1}$. The possible structure of this ion (hydroxybenzyl vs hydroxyltropylium) has been discussed by Russel et al. ${ }^{69}$ who measured its AE from a large variety of neutral precursors including 2-methylphenol. Their conclusion is that values around $730 \pm 10 \mathrm{~kJ} \mathrm{~mol}^{-1}$ correspond to the formation of the hydroxybenzyl cation. The hydroxyltropylium structure would have a lower heat of formation, by about $100 \mathrm{~kJ} \mathrm{~mol}^{-1}$.

The appearance energy of the $\mathrm{m} / \mathrm{z}=91$ is given in ref 70 to be $\mathrm{AE}=11.26 \pm 0.1 \mathrm{eV}$, yielding $\Delta_{\mathrm{f}} H^{\mathrm{app}}\left(\mathrm{C}_{7} \mathrm{H}_{7}{ }^{+}\right)=923.4 \pm$ $10 \mathrm{~kJ} \mathrm{~mol}^{-1}$ assuming loss of the $\mathrm{OH}$ radical. This leads us to assume a tropylium or benzylium structure for this ion.

We also measured the appearance energy of the $\mathrm{m} / \mathrm{z}=90$ cation to be $\mathrm{AE}=11.57 \pm 0.1 \mathrm{eV}$ (ion yield curve not shown). Assuming water loss, we determine $\Delta_{\mathrm{f}} H^{\mathrm{app}}\left(\mathrm{C}_{7} \mathrm{H}_{6}{ }^{+}\right)=1234.2$ $\pm 10 \mathrm{~kJ} \mathrm{~mol}^{-1}$. The structure of this ion, however, remains to be specified. Estimations for two $\mathrm{C}_{7} \mathrm{H}_{6}{ }^{+}$isomers are on the same order of magnitude compared to the present measurement (1150 and " $<1223$ " $\left.\mathrm{kJ} \mathrm{mol}^{-1}\right)^{51}$ and thus corroborate the hypothesis of $\mathrm{H}_{2} \mathrm{O}$ loss.

We measured the AE value of the $\mathrm{C}_{6} \mathrm{H}_{7}{ }^{+}$ion $(\mathrm{m} / \mathrm{z}=79)$ to be $\mathrm{AE}=11.33 \pm 0.1 \mathrm{eV}$ (ion yield curve not shown), in excellent agreement with ref 69. This ion is most probably formed by loss of $\mathrm{H}$ and $\mathrm{CO}$ from the parent cation (reaction 13), since the corresponding $\Delta_{\mathrm{f}} H^{\mathrm{app}}\left(\mathrm{C}_{6} \mathrm{H}_{7}{ }^{+}\right)=861.7 \pm 10$ $\mathrm{kJ} \mathrm{mol}^{-1}$ is in excellent agreement with $\Delta_{\mathrm{f}} H\left(\mathrm{C}_{6} \mathrm{H}_{7}{ }^{+}\right)=854$ $\mathrm{kJ} \mathrm{mol}^{-1}$ calculated from the proton affinity of benzene. ${ }^{51}$

$$
\mathrm{C}_{7} \mathrm{H}_{8} \mathrm{O}^{+}(m / z=108) \rightarrow \mathrm{C}_{6} \mathrm{H}_{7}{ }^{+}(m / z=79)+\mathrm{CO}+\mathrm{H}
$$

Our results thus suggest that $\mathrm{C}_{6} \mathrm{H}_{7}{ }^{+}$formed by reaction 13 has the ring-retaining, "protonated benzene" structure. Open chain structures for $\mathrm{C}_{6} \mathrm{H}_{7}{ }^{+}$can probably be excluded since they have much higher heats of formation. ${ }^{51}$

An $\mathrm{AE}$ value for the $\mathrm{C}_{6} \mathrm{H}_{5}{ }^{+}$ion is given in ref 70 (14.86 \pm $0.09 \mathrm{eV}$ ). The ion is probably formed by loss of $\mathrm{OH}$ and $\mathrm{CH}_{2}$ 
(reaction 14) since the deduced $\Delta_{\mathrm{f}} H^{\mathrm{app}}\left(\mathrm{C}_{6} \mathrm{H}_{5}{ }^{+}\right)=1132.4 \pm 10$ $\mathrm{kJ} \mathrm{mol}^{-1}$ is in excellent agreement with literature values of phenyl $^{+} .51$

$$
\mathrm{C}_{7} \mathrm{H}_{8} \mathrm{O}^{+}(m / z=108) \rightarrow \mathrm{C}_{6} \mathrm{H}_{5}{ }^{+}(m / z=77)+\mathrm{OH}+\mathrm{CH}_{2}
$$

Other ions observed in the $15 \mathrm{eV}$ mass spectrum are $\mathrm{m} / \mathrm{z}=$ 89 and 80. Their AEs have not been measured. The cation $\mathrm{m} / \mathrm{z}$ $=89\left(\mathrm{C}_{7} \mathrm{H}_{5}{ }^{+}\right)$might be formed by successive loss of $\mathrm{H}_{2} \mathrm{O}$ and $\mathrm{H}$. The formation pathway and molecular identity of the relatively intense ion with $\mathrm{m} / \mathrm{z}=80$ remain unclear.

4.2.6. o-Toluic acid, $\mathrm{C}_{8} \mathrm{H}_{8} \mathrm{O}_{2}$. In the atmosphere, $o$-toluic acid is the major degradation product of 2-methylstyrene, as can be concluded from SOA formation experiments in a smog chamber. ${ }^{67}$ In its PI mass spectrum recorded with zero-order light of the grating and applying the LiF filter, only two ions are present: the parent ion $(m / z=136)$, which is the most abundant ion, and the fragment ion $\mathrm{m} / \mathrm{z}=118$, with approximately $15 \%$ relative intensity of the parent cation. The ion $\mathrm{m} / \mathrm{z}=119$ is most probably the ${ }^{13} \mathrm{C}$ isotopomer since its intensity relative to $\mathrm{m} / \mathrm{z}=118$ corresponds exactly to the expected value for an isotopic ion (8.8\%). However, at $20 \mathrm{eV}$ EI the ion $\mathrm{m} / \mathrm{z}=119$ is much stronger than the expected ${ }^{13} \mathrm{C}$ isotopic mass peak, indicating additional pathways leading to its formation. The ions 91, 90, and 89 are not present in the mass spectrum obtained with zero-order light from the monochromator (plus LiF filter), indicating that these ions are formed above $11.8 \mathrm{eV}$ (cf. Table 1).

Our PIMS ionization energy of $o$-toluic acid, measured with the $\mathrm{LiF}$ filter, is $\mathrm{IE}=8.93 \pm 0.02 \mathrm{eV}$ (cf. Figure 7a,b). Only an earlier PES value is available in the literature, $\mathrm{IE}_{\mathrm{vert}}=9.1$ $\mathrm{eV},{ }^{72}$ being higher than our PI value (neither the adiabatic IE is given, nor the PE spectrum is displayed in ref 72). The gas phase heat of formation of the parent molecule is known from experiment (cf. Table 2); we can thus determine $\Delta_{\mathrm{f}} H$ (o-toluic $\left.\operatorname{acid}^{+}\right)=541 \pm 4 \mathrm{~kJ} \mathrm{~mol}^{-1}$.

The appearance energy of the intense $\mathrm{m} / \mathrm{z}=118$ ion, which is most probably formed by the loss of $\mathrm{H}_{2} \mathrm{O}$, is $\mathrm{AE}=10.17 \pm$ $0.05 \mathrm{eV}$ (cf. Figure 7c,d). We deduce $\Delta_{\mathrm{f}} H^{\mathrm{app}}\left(\mathrm{C}_{8} \mathrm{H}_{6} \mathrm{O}^{+}\right)=902.5$ $\pm 7 \mathrm{~kJ} \mathrm{~mol}^{-1}$. No data are found in the literature for $\mathrm{C}_{8} \mathrm{H}_{6} \mathrm{O}^{+}$.

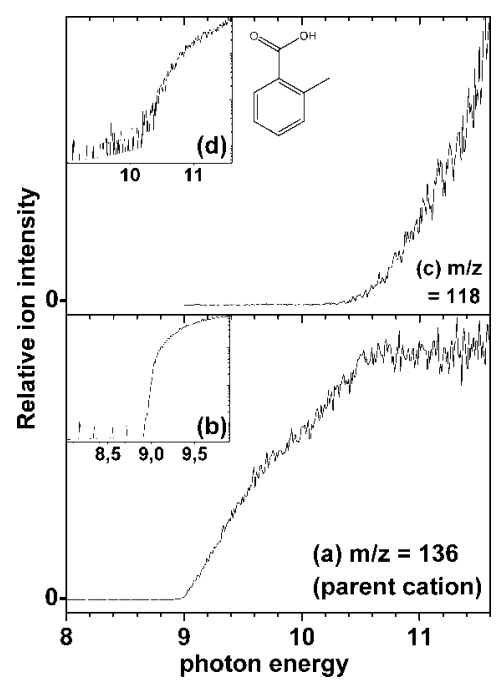

Figure 7. Photoion yield curves of $o$-toluic acid. (a) $\mathrm{m} / \mathrm{z}=136$ (parent ion, measured with LiF filter, linear scale). (b) Same measurement as for (a), $\log$ scale. (c) $\mathrm{m} / \mathrm{z}=118$ (measured with $\mathrm{LiF}$ filter, linear scale). (d) Same measurement as for (c), log scale.

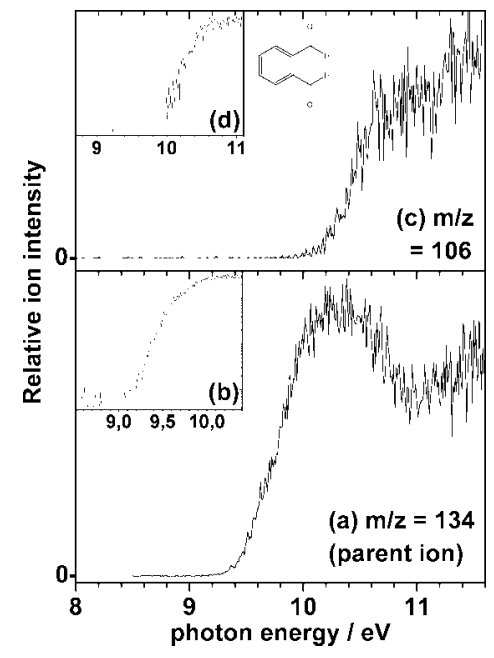

Figure 8. Photoion yield curves of phthaldialdehyde. (a) $\mathrm{m} / \mathrm{z}=134$ (parent ion, measured with LiF filter, linear scale). (b) Same measurement as for (a), log scale. (c) $\mathrm{m} / \mathrm{z}=106$ (measured with LiF filter, linear scale). (d) Same measurement as for (c), log scale.

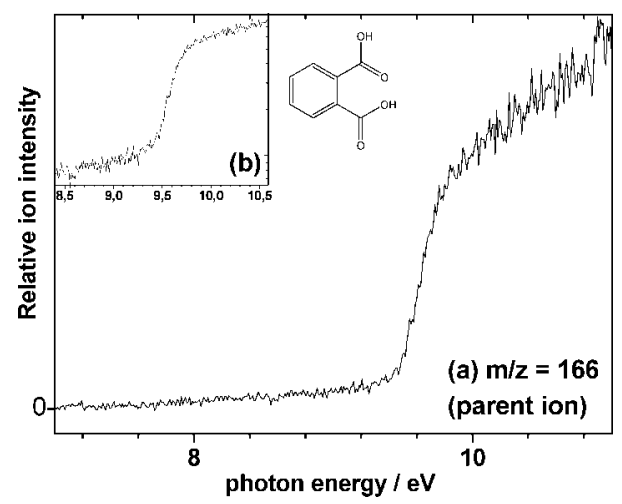

Figure 9. Photoion yield curves of the parent ion of phthalic acid (measured with LiF filter). (a) Linear scale; (b) log scale.

4.2.7. Phthaldialdehyde, $\mathrm{C}_{8} \mathrm{H}_{6} \mathrm{O}_{2}$. In the atmosphere, phthaldialdehyde is a major oxidation product of indene and 2-methylstyrene, according to smog chamber experiments. ${ }^{67}$ Our $15 \mathrm{eV}$ PI mass spectrum shows five strong ions $(\mathrm{m} / \mathrm{z}=134$, $106,105,78,77)$ and four weak ions $(\mathrm{m} / \mathrm{z}=107,79,76,51$ (cf. Table 1). All these ions are also found in the $20 \mathrm{eV}$ EI mass spectrum ${ }^{55}$ where, additionally, the $m / z=50,39$, and a few other weak ions are observed.

Our PIMS ionization energy is found at IE $=9.21 \pm 0.03$ eV (cf. Figure 8a,b). No thermodynamic data are available for this compound to our knowledge. Using the calculated $\Delta_{\mathrm{f}} H$ for phthaldialdehyde (G3B3 method, Table 2), we deduce $\Delta_{\mathrm{f}} H$ (phthaldialdehyde $\left.{ }^{+}\right)=759.3 \pm 8 \mathrm{~kJ} \mathrm{~mol}^{-1}$.

We measured the appearance energy of the $\mathrm{m} / \mathrm{z}=106$ ion, probably formed by loss of a $\mathrm{CO}$ molecule (and not $\mathrm{C}_{2} \mathrm{H}_{4}$ ), to be $\mathrm{AE}\left(\mathrm{C}_{7} \mathrm{H}_{6} \mathrm{O}^{+}\right)=9.95 \mathrm{eV} \pm 0.1 \mathrm{eV}$ (cf. Figure 8c,d; measured with $\mathrm{LiF}$ filter). We determined $\Delta_{\mathrm{f}} H^{\mathrm{app}}\left(\mathrm{C}_{7} \mathrm{H}_{6} \mathrm{O}^{+}\right)=941.2 \pm$ $15 \mathrm{~kJ} \mathrm{~mol}^{-1}$, which is relatively close to a value found for ionized cycloheptatrienon $\left(903 \mathrm{~kJ} \mathrm{~mol}^{-1}\right),{ }^{51}$ indicating that $\mathrm{C}_{7} \mathrm{H}_{6} \mathrm{O}^{+}$formed from phthaldialdehyde might have this structure. The AE of the $\mathrm{m} / \mathrm{z}=105$ ion, possibly formed by loss of the formyl radical, is found at $\mathrm{AE}\left(\mathrm{C}_{7} \mathrm{H}_{5} \mathrm{O}^{+}\right)=10.6 \pm 0.2 \mathrm{eV}$ (ion yield curve not shown; measured with $\mathrm{LiF}$ filter) from which $\Delta_{\mathrm{f}} H^{\mathrm{app}}\left(\mathrm{C}_{7} \mathrm{H}_{5} \mathrm{O}^{+}\right)=849.9 \pm 25 \mathrm{~kJ} \mathrm{~mol}^{-1}$. This is in disagreement with a value found for ionized $\mathrm{CO}$-substituted 


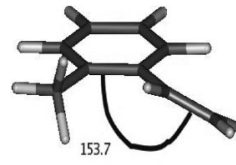

2-Methylstyrene $(\mathrm{N})$

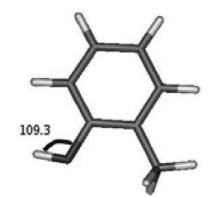

2-Methylphenol (N)

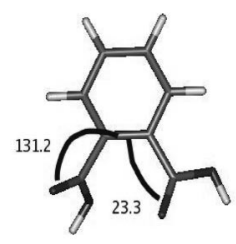

Phthalic Acid (N)

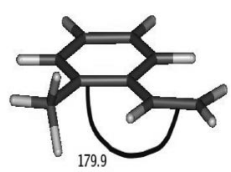

2-Methylstyrene (Cat.)

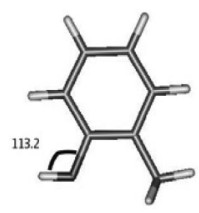

2-Methylphenol (Cat.)

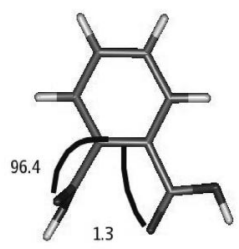

Phthalic Acid (Cat.)
Figure 10. Geometries of the neutral molecules $(\mathrm{N})$ and parent cations (Cat.), optimized using DFT (B3LYP functional/6-311++G** basis set). We only show those molecules where the geometry change is significant. The algebraic dihedral angle $(\overline{123})$ is formed by three ordered bonds: bonds 1 and 3 are those connected by the rounded line drawn in the picture, and bond 2 is the one lying between them.

benzene $\left(705 \pm 6 \mathrm{~kJ} \mathrm{~mol}^{-1}\right) .{ }^{51}$ Additional calculations are necessary in order to derive the structure of the ions $\mathrm{m} / \mathrm{z}=106$ and 105 .

4.2.8. Phthalic acid, $\mathrm{C}_{8} \mathrm{H}_{6} \mathrm{O}_{4}$. In the atmosphere, phthalic acid is a major oxidation product of indene, according to smog chamber experiments. ${ }^{67}$ The $15 \mathrm{eV}$ PI mass spectrum shows four ions, with $m / z=166,148,104$, and 76. As discussed in section 2, the $15 \mathrm{eV}$ PI mass spectrum also contains mass peaks form benzoic acid, formed by thermal decomposition of phthalic acid inside the ionization region (mainly $\mathrm{m} / \mathrm{z}=122$ and 105; not listed in Table 1).

The PIMS ionization energy measured for this compound is $9.42 \pm 0.03 \mathrm{eV}$ (cf. Figure 9a,b). We deduce $\Delta_{\mathrm{f}} H$ (phthalic $\left.\operatorname{acid}^{+}\right)=257.6 \pm 4 \mathrm{~kJ} \mathrm{~mol}^{-1}$. No gas phase ion energetics data are available for this compound in the literature. We note however, that the IEs of the isomers 1,3- and 1,4-benzenedicarboylic acid can be found in ref $51(9.98 \pm 0.2$ and $9.86 \pm$ $0.2 \mathrm{eV}$, respectively). As is the case for $o$-tolualdehyde, the substituent in the ortho position reduces the IE by several hundred millielectronvolts. Theoretical work is in progress to understand this considerable shift.

The appearance energy of the $\mathrm{m} / \mathrm{z}=148$ ion has been determined to be $\mathrm{AE}=10.1 \pm 0.1 \mathrm{eV}$ (ion yield curve not shown). This ion is probably formed by loss of a water molecule from the parent cation to give rise to the formation of a phthalic anhydride cation $\left(\mathrm{C}_{6} \mathrm{H}_{4} \mathrm{O}_{3}{ }^{+}\right)$. However, we cannot exclude that our $m / z=148$ mass peak might be, at least in part, due to ionization of neutral phthalic anhydride formed by thermal dehydration of phthalic acid in the ionization region $\left(\mathrm{IE}_{\mathrm{vert}}(\mathrm{ph}-\right.$ thalic anhydride) $=10.25 \pm 0.05 \mathrm{eV}^{73}$ ).

Additional loss of $\mathrm{CO}_{2}$ and $\mathrm{CO}$ produces the ions $\mathrm{m} / \mathrm{z}=104$ and 76. The ion yield curves of these two ions have not been measured. The $\mathrm{m} / \mathrm{z}=104$ ion is visible in a zero-order mass spectrum (plus LiF filter); its AE has thus to be below $11.8 \mathrm{eV}$.

4.3. Ab Initio Calculations of Adiabatic Ionization Energies. 4.3.1. Geometries. The geometries were optimized with B3LYP functional and the three above-mentioned basis sets.
The stationary points were all minima. In Figure 10 we show results obtained with the B3LYP/6-311++G** basis set, which are quite similar to those obtained with the other two basis sets. We only show those molecules where the geometry change from the neutral to the cation is significant, i.e., 2-methylstyrene, 2-methylphenol, and phthalic acid.

For the following systems the carbon backbone was found to be nearly planar, both for the neutral and for the cationic system: $o$-tolualdehyde, 2-methylphenol, phthalic anhydride, $o$-toluic acid, phthaldialehyde, indene, and $o$-xylene. In neutral 2-methylstyrene the (trans) vinyl substituent is slightly inclined out of the cycle plane, whereas in the cationic form the vinyl group is coplanar with the cycle. In neutral phthalic acid, the carbonyl oxygen of the first acid function, which is inclined with respect to the cycle plane by $131.2^{\circ}$, is slightly hydrogenbonded $\left(d_{\mathrm{O}-\mathrm{H}}=3.33 \AA\right.$ ) with the hydroxide of the second acid function being also inclined with respect to the cycle plane, by $23.3^{\circ}$. In cationic phthalic acid the inclination of the first acid function is even more pronounced, now being almost perpendicular to both the cycle and the second acid function which is almost coplanar to the cycle.

4.3.2. Adiabatic Ionization Energies. All numerical results for the adiabatic ionization energies are reported in Table 3. First, it should be noted that the B3LYP ZPE corrections are very close $(\Delta<15 \mathrm{meV})$ for the neutral molecule and its respective adiabatic cation in the following cases: 2-methylstyrene 2-methylphenol, phthalic acid, and indene (cf. Table 3). On the other hand, for $o$-tolualdehyde, phthalic anhydride, $o$-toluic acid, phthaldialdehyde, and $o$-xylene, the ZPE correction for the neutral and the cation can differ by up to $100 \mathrm{meV}$. We conclude that neglecting the ZPE for this kind of molecules, as proposed in ref 39 for nucleobases, could be a significant source of error. In the present work, the ZPE corrections were taken into account at the B3LYP level of the calculations.

Clearly, a more important factor acting on the accuracy of the IE values is the choice of (a) the method for the single point energy calculation and (b) the basis set. The significant variation of the calculated IE which we observe when changing method and basis set (up to several hundred millielectronvolts, cf. Table 3) actually underlines the importance of studying the convergence of the calculations in order to get confidence in the results.

4.3.2.1. Method Comparison for the Calculation of Adiabatic Ionization Energies: Density Functional Theory. B3LYP density functional often gives quite reasonable results for the ionization energies. The deviation with respect to the experimental value is usually about $0.2 \mathrm{eV}$ or better provided that the basis set is large enough (6-311++ $\mathrm{G}^{* *}$ and cc-pVTZ are clearly better than $6-31 G(d, p))$. This indicates that polarization and diffuse functions are important. For phthalic acid the calculated deviations from the experiment are found to be larger $(-0.31$ and -0.42 $\mathrm{eV})$. The reason for this is that the cation has two configurations with $\beta-\beta$ spin interaction, with the following amplitudes at the $\operatorname{CCSD}(\mathrm{T}) / 6-311++\mathrm{G}^{* *}$ level: 0.26 and -0.21 . This indicates a nonnegligible multireference character which is known to be a challenge for density functionals as well as for wave-functionbased single reference methods used in the present work. To a smaller extent, in cationic $o$-tolualdehyde, two configurations show evidence of $\alpha-\alpha$ and $\beta-\beta$ spin interactions, with amplitudes 0.11 and 0.11 , respectively. In cationic 2-methylstyrene, one configuration shows $\alpha-\alpha$ spin interaction, with an amplitude of 0.10 .

4.3.2.2. Method Comparison for the Calculation of Adiabatic Ionization Energies: Wave Function Methods. In order to further improve these results in a systematic way, we investigated the 


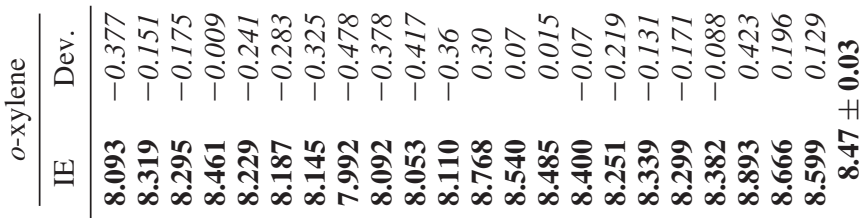

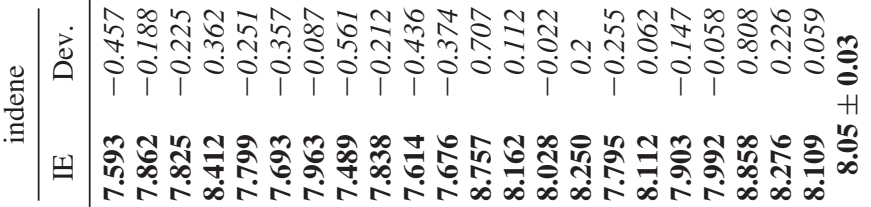

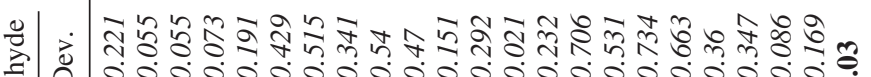
产

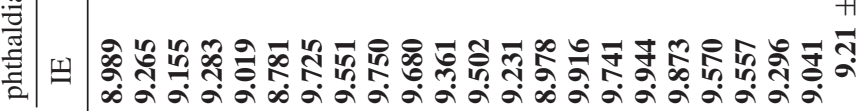

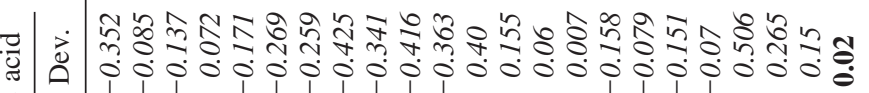

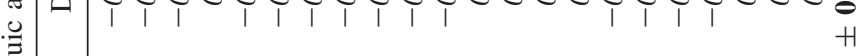

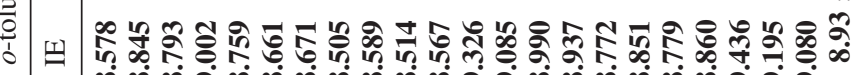

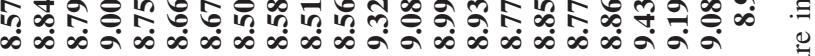

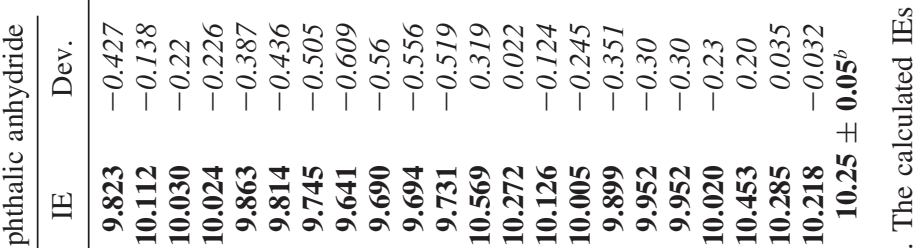

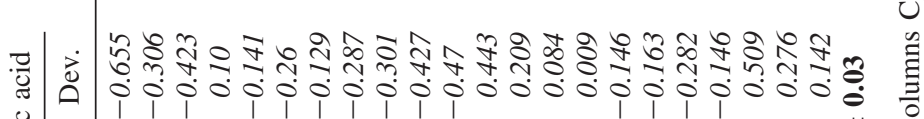

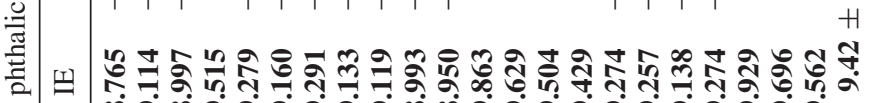

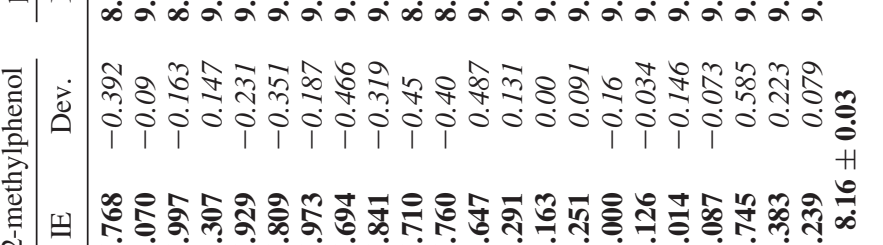
त|

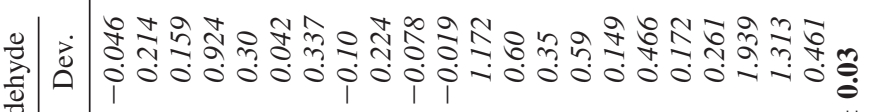

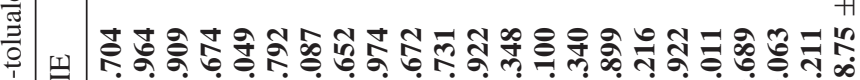

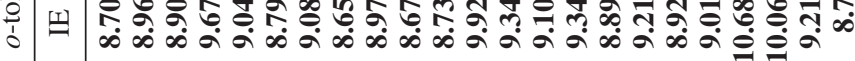

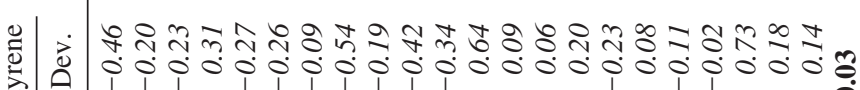

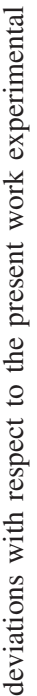

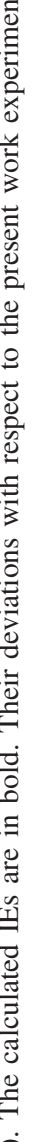
$\frac{0}{8}$ 告)

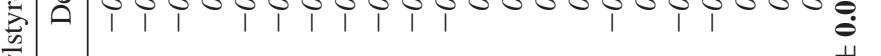

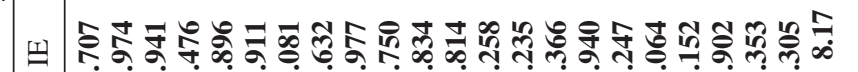

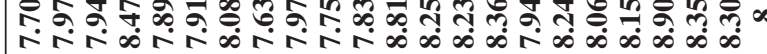

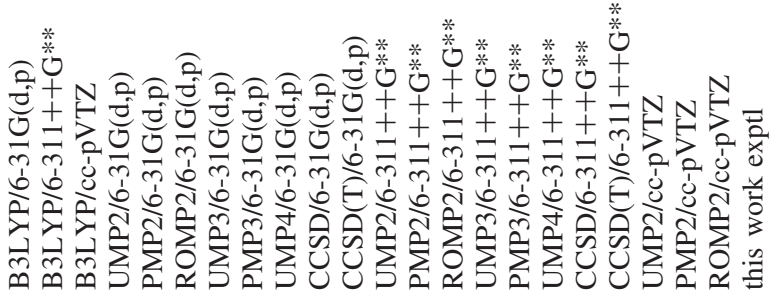
(2) 
IE calculations with wave function methods, by increasing gradually the complexity in the following order: MP2 < MP3 $<\mathrm{MP} 4 \leq \mathrm{CCSD}<\mathrm{CCSD}(\mathrm{T})$. As a general trend, we found that, for a given basis set, the discrepancy with the experiment is decreasing (in algebraic value) with the level of the method. The exception is phthaldialdehyde, where the deviation using the UMP3 method is much larger than when using UMP2, thus showing a nonmonotonic behavior of the perturbation series. Moreover, the sign of the discrepancy with respect to the experiment was sometimes found to vary by increasing the level of the method for a given basis set, which can be understood by the fact that no variational principle is available for the IEs, and that the convergence of the results has not been fully reached.

The UMP2 results overestimate seriously the IEs due to spin contamination of the cation. A similar conclusion was drawn for DNA/RNA bases, which contain aromatic rings as well, in the work reported in refs 74 and 75 . Our deviation to the experiment can reach up to $0.71 \mathrm{eV}$ (indene), versus $0.80 \mathrm{eV}$ in ref 74 and $0.9 \mathrm{eV}$ in ref 75 . We point out the exception of $o$-tolualdehyde in our case, where the discrepancy can be as large as $1.94 \mathrm{eV}$ even though this error is reduced significantly by improving the method.

As is the case in the work presented in refs 74 and 75, the spin contamination error could be significantly reduced by using the projection technique of Schlegel ${ }^{34}$ (to $0.02-0.21 \mathrm{eV}$ in our case with PMP2/6-311++ $\left.\mathrm{G}^{* *}\right)$. We still mention the exception of $o$-tolualdehyde, where the PMP2 error $(0.60 \mathrm{eV})$ remains large in those conditions, even if it has been greatly reduced with respect to the UMP2 method $(1.17 \mathrm{eV})$.

The restricted open-shell (ROHF) reference wave function was used as a possible alternative. It was found to improve the results yielding $0.00-0.23 \mathrm{eV}$ deviation from the experiment, depending on the molecule (cf. Table 3, ROMP2/6-311++ $\mathrm{G}^{* *}$ ). Similar trends were obtained by Cauët et al. ${ }^{39}$ We still keep the exception of $o$-tolualdehyde ranging outside the mentioned error regime, i.e., $0.35 \mathrm{eV}$ error.

It is noteworthy that projected second-order results are often better than projected third-order results (see, for example, PMP3/ $6-311++\mathrm{G}^{* *}$ yielding relatively large errors, from -0.255 to $0.53 \mathrm{eV})$. The MP4/6-311++G** results $(-0.163$ to $0.73 \mathrm{eV}$ error domain) are sometimes an improvement with respect to MP3, and sometimes a deterioration, depending on whether the IE of the considered molecule was located above or below the experimental value at third order. The same applies to the CCSD ( -0.282 to $0.66 \mathrm{eV}$ error domain) and $\operatorname{CCSD}(\mathrm{T})$ methods $(-0.146$ to $0.36 \mathrm{eV})$ where the improvement with respect to MP4 is not systematic.

4.3.3. Basis Set Effects. Density functionals are known to converge relatively fast with the basis set. This is also the case in our calculations (cf. Table 3). Concerning wave function calculations, however, the convergence with the basis set is not so fast. It can be concluded, by inspection of the results, that the convergence has not been achieved for the systems presently studied with the $6-311++\mathrm{G}^{* *}$ basis set. This is of course due to a practical limitation: the large number of electrons $(58-86)$, combined with the high scaling of the methods used $\left(N^{5}\right.$ for MP2 to $N^{7}$ for CCSD(T), $N$ being proportional to the size of the system). As a consequence, a close agreement with the experimental data will only be obtained through favorable error cancelations. It can be seen that the results are poor if the basis set is too small $(6-31 \mathrm{G}(\mathrm{d}, \mathrm{p}))$, especially when the method is of high level $(\operatorname{CCSD}(\mathrm{T}))$. Thus, if the basis set is small, it is not of much use to refine the method too much. In conclusion, one has to find a balance between the size of the basis and the level of the method.

For the molecules under study here, the results with the 6-31G(d,p) basis set are clearly not good enough, whereas they are significantly better with the $6-311++\mathrm{G}^{* *}$ basis set which contains diffuse, and additional polarization functions. Indeed, going from $\operatorname{CCSD}(\mathrm{T}) / 6-31 \mathrm{G}(\mathrm{d}, \mathrm{p})$ to $\operatorname{CCSD}(\mathrm{T}) / 6-311++\mathrm{G}^{* *}$ yields the following significant improvements: for 2-methylstyrene, from to -0.34 to $-0.02 \mathrm{eV}$ deviation from experiment; for 2-methylphenol, from -0.4 to $-0.073 \mathrm{eV}$; for phthalic acid, from -0.47 to $-0.146 \mathrm{eV}$; for $o$-toluic acid, from -0.363 to $-0.07 \mathrm{eV}$; for phthalic anhydride; from -0.519 to $-0.23 \mathrm{eV}$; and for indene, from -0.374 to $-0.058 \mathrm{eV}$. On the contrary, when applying the $\operatorname{CCSD}(\mathrm{T})$ method to $o$-tolualdehyde, the basis set should not be too large: $6-31 \mathrm{G}(\mathrm{d}, \mathrm{p})$ yields $-0.02 \mathrm{eV}$ whereas the same method with the $6-311++\mathrm{G}^{* *}$ basis set yields 0.26 $\mathrm{eV}$ deviation from the experiment. For phthaldialehyde (deviation from experiment from 0.15 to $0.36 \mathrm{eV}$ ), perturbations show up an nonmonotonic behavior when going from one order to the next one, and this effect is even amplified by enlarging the basis set from $6-31 \mathrm{G}(\mathrm{d}, \mathrm{p})$ to $6-311++\mathrm{G}^{* *}$. By contrast, this behavior was found to disappear with the STO-3G minimal valence basis set which is otherwise unfortunately too poor to get quantitative agreement with the experiment, suggesting that the presence of diffuse functions might be the cause of the convergence problems that are presently encountered.

We conclude that, as a rule, second-order Møller-Plesset perturbations perform relatively well to predict the experimental IEs provided that a sufficiently large basis set is used (6$311++\mathrm{G}^{* *}$ and cc-pVTZ, for example) and one has corrected for spin contamination, preferably with the ROMP2 formalism. The more expensive unrestricted coupled-cluster methods are normally expected to give even better results. However, there is no improvement in cases where the single reference perturbation series either does not converge satisfactorily (phthaldialdehyde with $\operatorname{CCSD}(\mathrm{T}) / 6-311++\mathrm{G}^{* *}$ ) or is still not converged at the present highest level of calculations (phthalic anhydride with $\left.\operatorname{CCSD}(\mathrm{T}) / 6-311++\mathrm{G}^{* *}\right)$.

\section{Conclusion}

Photoionization mass spectrometry (PIMS) in connection with synchrotron radiation has been used to study the VUV photoionization $(7-15 \mathrm{eV})$ of three anthropogenic volatile organic compounds (AVOCs), o-xylene, 2-methylstyrene, and indene, as well as five of their atmospheric degradation products: $o$-tolualdehyde, $o$-toluic acid, 2-methylphenol, phthaldialdehyde, and phthalic acid. The aim of our study was to measure and/or calculate relevant thermodynamic data, such as ionization energies, fragment appearance energies, and heats of formation, hitherto unknown for the observed parent and fragment ions. Moreover, we analyzed the VUV degradation pathways of the molecules under investigation.

In the experimental part of our study, the following results have been obtained: Ionization and fragmentation appearance energies have been measured with single photon ionization. This ionization technique has never been used in the past for seven of the eight compounds under study in this work. Single photon ionization is known for high ionization cross sections in the VUV, and is thus specially adapted to measure IE and AE thresholds. The obtained values are mostly lower than those obtained from earlier electron impact ionization measurements. For two molecules (phthalic acid and phthaldialdehyde), the IE was not known at all before. The measured IEs are also in good agreement with IEs determined from PES. The results enabled 
us to calculate apparent heats of formation of parent and fragment ions. For the latter, we compared their $\Delta_{\mathrm{f}} H^{\text {app }}$ values to literature data, when available, and in several cases, chemical structures have been proposed for the ions and related fragmentation pathways have been suggested or confirmed. For many ionic fragmentation reactions, no AE measurements had been carried out before.

In the theoretical part of our study, we performed intensive quantum chemical calculations, on (i) the adiabatic ionization energies of the molecules studied experimentally (including also phthalic anhydride) and (ii) the heats of formation of the neutral molecules:

(i) Adiabatic ionization energies have been calculated with the aim to find the best computational method to calculate IEs for the species under study and to predict them for chemically related molecules. To our opinion, it is clear from the literature that there is no general, "state-of-the-art" method to compute first ionization energies from ab initio quantum chemical calculations, applicable for every kind of molecule. Rather, for each type of molecular system, the best method has to be found by means of careful theoretical studies.

As a general conclusion, for the molecules under study here and chemically related species, we recommend second-order Møller-Plesset perturbations with large basis sets $\left(6-311++\mathrm{G}^{* *}\right.$ and cc-pVTZ), corrected for spin contamination with the ROMP2 formalism. The more expensive unrestricted coupledcluster methods do not give a significant further improvement at the present highest level of calculations $(\operatorname{CCSD}(\mathrm{T}) / 6-$ $\left.311++\mathrm{G}^{* *}\right)$. A ZPE correction has to be included, too.

(ii) Heats of formation have been calculated with the aim to verify the accuracy of "state-of-the-art" methods (G2MP2, G3B3) for the molecules investigated here. G2B2 and G3B3 methods are rarely used for molecules of the size of those studied in this paper. According to our results, these methods can indeed be used for small aromatic molecules carrying methyl, hydroxy, aldehyde, or acid functions, once a deviation of up to $5 \mathrm{~kJ} \mathrm{~mol}^{-1}$ from the true value is acceptable. We have used the calculated heats of formation for analyzing the thermochemistry of ionic fragmentation reactions in cases where an experimental value was not available.

As has been demonstrated in the discussion, the thermochemical analysis of a fragmentation reaction often permits constructive conclusions as to the identity of the neutrals and ionic fragments. In the future we intend to calculate also heats of formation of neutral and cationic fragments produced in dissociative ionization. Those are often open-shell species and thus calculation is a priori more difficult, but would help certainly to further clarify fragmentation pathways.

Experimental and theoretical results from this study are important with respect to the analytical chemistry of the compounds. They will help (1) to assign mass peaks from photoionization mass spectrometry experiments relying on monochromatic radiation and (2) in the analysis and comprehension of online mass spectra of complex mixtures of environmental importance, such as atmospheric aerosols. Furthermore, research groups studying SOA formation can use the theoretical methods proposed here to predict IEs and $\Delta_{\mathrm{f}} H$ values when needed for the interpretation of online mass spectra.

Acknowledgment. The PIMS experimental studies were performed at the BESSY II synchrotron radiation facility in Berlin, Germany. We thank Dr. Gerd Reichardt for excellent support during the beam-time periods. This work was supported by the BESSY IA-SFS program. The following calculation facilities are acknowledged for generous allocation of calculation time: Centre de Calculs Recherche et Enseignement (CCRE), Université Pierre et Marie Curie (Paris); Direction Informatique (DI), Université Paris-Sud (Orsay, France); Institut du Développement et des Ressources Informatiques (IDRIS) (Orsay, France); Centre Informatique National de l'Enseignement Supérieur (CINES) (Montpellier, France). The authors wish to thank Dr. Sydney Leach (Observatoire de Paris-Meudon) and Prof. Dr. Attila G. Császár (Eötvös Loránd University, Budapest) for helpful discussions.

Note Added after ASAP Publication. This paper was published ASAP on May 21, 2008. A misspelled author name was corrected. The revised paper was reposted on June 5, 2008.

\section{References and Notes}

(1) Jaenicke, R. Global Aerosols. In Observed Global Climate; LandoltBörnstein Numerical Data and Functional Relationships in Science and Technology, New Series, Group V: Geophysics, Vol. 6; Springer: Berlin, Heidelberg, Germany, 2005.

(2) Climate Change 2007-The Physical Science Basis. Working Group I Contribution to the Fourth Assessment Report of the IPCC (Intergovernmental Panel on Climate Change); Cambridge University Press: Cambridge, 2007.

(3) Putaud, J. P.; Raes, F.; Van Dingenen, R.; Brüggemann, E.; Facchini, M. C.; Decesari, S.; Fuzzi, S.; Gehrig, R.; Hüglin, C.; Laj, P.; Lorbeer, G.; Maenhaut, W.; Mihalopoulos, N.; Müller, K.; Querol, X.; Rodriguez, S.; Schneider, J.; Spindler, G.; ten Brink, H.; Tørseth, K.; Wiedensohler, A. Atmos. Environ. 2004, 38, 2579.

(4) Andreae, M. O.; Crutzen, P. J. Science 1997, 276, 1052.

(5) Schauer, J. J.; Rogge, W. F.; Hildemann, L. M.; Mazurek, M. A.; Cass, G. R. Atmos. Environ. 1996, 30, 3837.

(6) Kanakidou, M.; Seinfeld, J. H.; Pandis, S. N.; Barnes, I.; Dentener, F. J.; Facchini, M. C.; van Dingenen, R.; Ervens, B.; Nenes, A.; Nielsen, C. J.; Swietlicki, E.; Putaud, J. P.; Balkanski, Y.; Fuzzi, S.; Horth, J.; Moortgat, G. K.; Winterhalter, R.; Myhre, C. E.; Tsigaridis, K.; Vignati, E.; Stephanou, E. G.; Wilson, J. Atmos. Chem. Phys. 2005, 5, 1053.

(7) Tsigaridis, K.; Kanakidou, M. Atmos. Chem. Phys. 2003, 3, 1849.

(8) Volkamer, R.; Jiminez, J. L.; San Martini, F.; Dzepinal, K.; Zhang, Q.; Salcedo, D.; Molina, L. T.; Worsnop, D. R.; Molina., M. J. Geophys. Res. Lett. 2006, 33, L17811.

(9) Rissanen, T. R.; Hyötyläinen, T.; Kallio, M.; Kronholm, J.; Kulmala, M.; Riekkola, M.-J. Chemosphere 2006, 64, 1185.

(10) Böge, O.; Miao, Y.; Plewka, A.; Herrmann, H. Atmos. Environ. 2006, 40, 2501.

(11) Chiappini, L.; Carrasco, N.; Temine, B.; Piquet-Varrault, B.; Durand-Jolibois, R.; Wenger, J. C.; Doussin, J. F. Environ. Chem. 2006, 3, 286.

(12) Alfarra, M. R.; Paulsen, D.; Gysel, M.; Garforth, A. A.; Dommen, J.; Prévôt, A. S. H.; Worsnop, D. R.; Baltensperger, U.; Coe, H. Atmos. Chem. Phys. 2006, 6, 5279.

(13) Huang, M.; Zhang, W.; Hao, L.; Wang, Z.; Zhao, W.; Gu, X.; Guo, X.; Liu, X.; Fang, L. J. Atmos. Chem. 2007, 58, 237.

(14) Woods, E., III; Smith, G. D.; Dessiaterik, Y.; Baer, T.; Miller, R. E. Anal. Chem. 2001, 73, 2317.

(15) Bente, M.; Adam, T.; Ferge, T.; Gallavardin, S.; Sklorz, M.; Streibel, T.; Zimmermann, R. Int. J. Mass Spectrom. 2006, 258, 86.

(16) Erdmann, N.; Dell' Acqua, A.; Cavalli, P.; Grüning, C.; Omenetto, N.; Putaud, J. P.; Raes, F.; Van Dingenen, R. Aerosol Sci. Technol. 2005, $39,377$.

(17) Vogt, R.; Kirchner, U.; Scheer, V.; Hinz, K. P.; Trimborn, A.; Spengler, B. J. Aerosol Sci. 2003, 34, 319.

(18) (a) Mysak, E. R.; Wilson, K. R.; Jimenez-Cruz, M.; Ahmed, M.; Baer, T. Anal. Chem. 2005, 77, 5953. (b) Grimm, M.; Langer, B.; Schlemmer, S.; Lischke, T.; Becker, U.; Widdra, W.; Gerlich, D.; Flesch, R.; Rühl, E. Phys. Rev. Lett. 2006, 96, 066801. (c) Shu, J.; Wilson, K. R.; Ahmed, M.; Leone, S. R.; Graf, C.; Rühl, E. J. Chem. Phys. 2006, 124, 034707. (d) Wilson, K.; Zou, S.; Shu, J.; Rühl, E.; Leone, S. R.; Schatz, G. C.; Ahmed, M. Nano Lett. 2007, 7, 2014.

(19) Gloaguen, E.; Mysak, E. R.; Leone, S. R.; Ahmed, M.; Wilson, K. R. Int. J. Mass Spectrom. 2006, 258, 74.

(20) Jochims, H.-W.; Schwell, M.; Baumgärtel, H.; Leach, S. Chem. Phys. 2005, 314, 263.

(21) Schwell, M.; Dulieu, F.; Gée, C.; Jochims, H.-W.; Chotin, J. L.; Baumgärtel, H.; Leach, S. Chem. Phys. 2000, 260, 261.

(22) Frisch, M. J.; Trucks, G. W.; Schlegel, H. B.; Scuseria, G. E.; Robb, M. A.; Cheeseman, J. R.; Montgomery, J. A., Jr.; Vreven, T.; Kudin, K. N.; Burant, J. C.; Millam, J. M.; Iyengar, S. S.; Tomasi, J.; Barone, V.; 
Mennucci, B.; Cossi, M.; Scalmani, G.; Rega, N.; Petersson, G. A.; Nakatsuji, H.; Hada, M.; Ehara, M.; Toyota, K.; Fukuda, R.; Hasegawa, J.; Ishida, M.; Nakajima, T.; Honda, Y.; Kitao, O.; Nakai, H.; Klene, M.; Li, X.; Knox, J. E.; Hratchian, H. P.; Cross, J. B.; Bakken, V.; Adamo, C.; Jaramillo, J.; Gomperts, R.; Stratmann, R. E.; Yazyev, O.; Austin, A. J.; Cammi, R.; Pomelli, C.; Ochterski, J. W.; Ayala, P. Y.; Morokuma, K.; Voth, G. A.; Salvador, P.; Dannenberg, J. J.; Zakrzewski, V. G.; Dapprich, S.; Daniels, A. D.; Strain, M. C.; Farkas, O.; Malick, D. K.; Rabuck, A. D.; Raghavachari, K.; Foresman, J. B.; Ortiz, J. V.; Cui, Q.; Baboul, A. G.; Clifford, S.; Cioslowski, J.; Stefanov, B. B.; Liu, G.; Liashenko, A.; Piskorz, P.; Komaromi, I.; Martin, R. L.; Fox, D. J.; Keith, T.; Al-Laham, M. A.; Peng, C. Y.; Nanayakkara, A.; Challacombe, M.; Gill, P. M. W.; Johnson, B.; Chen, W.; Wong, M. W.; Gonzalez, C.; Pople, J. A. Gaussian 03, revision C.02; Gaussian, Inc.: Wallingford, CT, 2004.

(23) Lee, C.; Yang, W.; Parr, R. G. Phys. Rev. B 1988, 37, 785.

(24) Becke, A. D. J. Chem. Phys. 1993, 98, 5648.

(25) Møller, C.; Plesset, M. S. Phys. Rev. 1934, 46, 618.

(26) Pople, J. A.; Seeger, R.; Krishnan, R. Int. J. Quantum Chem., Symp. 1977, 11, 149.

(27) Pople, J. A.; Binkley, J. S.; Seeger, R. Int. J. Quantum Chem., Symp. 1976, 10,1 .

(28) Krishnan, R.; Pople, J. A. Int. J. Quantum Chem. 1978, 14, 91.

(29) Cizek, J. Adv. Chem. Phys. 1969, 14, 35.

(30) Purvis, G. D.; Bartlett, R. J. J. Chem. Phys. 1982, 76, 1910.

(31) Scuseria, G. E.; Janssen, C. L.; Schaefer, H. F., III J. Chem. Phys. 1988, $89,7382$.

(32) Scuseria, G. E.; Schaefer, H., III F. J. Chem. Phys. 1989, 90, 3700.

(33) Pople, J. A.; Head-Gordon, M.; Raghavachari, K. J. Chem. Phys.

1987, $87,5968$.

(34) Schlegel, H. B. J. Chem. Phys. 1986, 84, 4530.

(35) Hariharan, P. C.; Pople, J. A. Theor. Chim. Acta 1973, 28, 213.

(36) Krishnan, R.; Binkley, J. S.; Seeger, R.; Pople, J. A. J. Chem. Phys. 1980, 72,650 .

(37) Clark, T.; Chandrasekhar, J.; Schleyer, P. v. R. J. Comput. Chem.

1983, 4, 294

(38) Dunning, T. H., Jr J. Chem. Phys. 1989, 90, 1007.

(39) Cauët, E.; Dehareng, D.; Liévin, J. J. Phys. Chem. A 2006, 110, 9200.

(40) Sponer, J.; Hobza, P. J. Phys. Chem. 1994, 98, 3161.

(41) Wintjens, R.; Biot, C.; Rooman, M.; Liévin, J. J. Phys. Chem. A 2003, 107, 6249 .

(42) Cauët, E.; Rooman, M.; Wintjens, R.; Liévin, J.; Biot, C. J. Chem. Theory Comput. 2005, 1, 472.

(43) Curtiss, L. A.; Raghavachari, K.; Pople, J. A. J. Chem. Phys. 1993, 98, 1293

(44) Baboul, A. G.; Curtiss, L. A.; Redfern, P. C.; Raghavachari, K. J. Chem. Phys. 1999, 110, 7650.

(45) Nicolaides, A.; Radom, L. Mol. Phys. 1996, 88, 759.

(46) Hehre, W. J.; Radom L.; Pople, J. A. Ab Initio Molecular Orbital Theory; Wiley: New York, 1986.

(47) Raghavachari, K.; Stefanov, B. B.; Curtiss, L. A. Mol. Phys. 1997, 91, 555 .

(48) Baer, T.; Mayer, P. M. J. Am. Soc. Mass Spectrom. 1997, 8, 103.

(49) Chupka, W. A. J. Chem. Phys. 1959, 30, 191.

(50) Jochims, H. W.; Rühl, E.; Baumgärtel, H.; Tobita, S.; Leach, S. Astrophys. J. 1994, 420, 307.

(51) Lias, S. G.; Bartmess, J. E.; Liebmann, J. F.; Holmes, J. L.; Levin, R. D.; Mallard, W. G. Gas phase ion and neutral thermochemistry. J. Phys. Chem. Ref. Data 1988, 17, Suppl. 1.
(52) Raghavachari, K.; Stefanov, B. B.; Curtiss, L. A. J. Chem. Phys. 1997, 106, 6764 .

(53) Notario, R.; Castano, O.; Abboud, J.-L. M.; Gomperts, R.; Frutos, L. M.; Palmeiro, R. J. Org. Chem. 1999, 64, 9011.

(54) (a) Dunietz, B. D.; Murphy, R. B.; Friesner, R. J. Chem. Phys. 1999, 110, 1921. (b) Parthiban, S.; Martin, J. M. L. J. Chem. Phys. 2001, 114, 6014. (c) Taji, A.; Szalay, P. G.; Csaszar, A. G.; Kallay, M.; Gauss, J.; Valeev, E. F.; Flowers, B. A.; Vazquez, J.; Stanton, J. F. J. Chem. Phys. 2004, 121, 11599.

(55) http://webbook.nist.gov.

(56) Watanabe, K. J. Chem. Phys. 1957, 26, 542.

(57) Loudon, A. G.; Mazengo, R. Z. Org. Mass Spectrom. 1974, 8, 179.

(58) Maier, J. P.; Turner, D. W. J. Chem. Soc., Faraday Trans. 2 1973, 69, 196.

(59) Prosen, E. J.; Gilmont, R.; Rossini, F. D. J. Res. Natl. Bur. Stand. $1945,34,65$.

(60) Akopyan, M. E.; Vilesov, F. I. Khim. Vys. Energ. 1968, 2, 107.

(61) Nounou, P. J. Chim. Phys. 1966, 63, 994.

(62) Köppel, C.; Schwarz, H.; Bohlmann, F. Org. Mass Spectrom. 1974,

8,25

(63) Schwarz, H.; Bohlmann, F. Org. Mass Spectrom. 1973, 7, 395.

(64) Occolowitz, J. L.; White, G. L. Aust. J. Chem. 1968, $21,997$.

(65) Rakita, P. E.; Hoffmann, M. K.; Andrews, M. N.; Bursey, M. M.

J. Organomet. Chem. 1973, 49, 213.

(66) Güsten, H.; Klasinc, L.; Ruščić, B. Z. Naturforsch., A 1976, 31, 1051.

(67) Chiappini, L. Ph.D. Thesis, University of Paris Diderot, 2006.

(68) Atkinson, R. S.; Aschmann, M.; Arey, J. Int. J. Chem. Kinet. 1991, $23,77$.

(69) Russel, D. H.; Freiser, B. S.; McBay, E. H.; Canada, D. C. Org. Mass Spectrom. 1983, 18, 474.

(70) Selim, E. T. M.; Fahmey, M. A.; Ghonime, H. S. Org. Mass Spectrom. 1991, 26, 55 .

(71) Maier, J. P.; Turner, D. W. J. Chem. Soc., Faraday Trans. 2 1973, 69, 521 .

(72) Meeks, J.; Wahlborg, A.; McGlynn, S. P. J. Electron Spectrosc. Relat. Phenom. 1981, 22, 43.

(73) Galasso, V.; Colonna, F. P.; Distefano, G. J. Electron Spectrosc. Relat. Phenom. 1977, 10, 227.

(74) Crespo-Hernandez, C. E.; Arce, R.; Ishikawa, Y.; Gorb, L.; Leszczynsky, J.; Close, D. M. J. Phys. Chem. A 2004, 108, 6373.

(75) Roca-Sanjuán, D.; Rubio, M.; Merchán, M.; Serrano-Andrés, L. J. Chem. Phys. 2006, 125, 84302 .

(76) Yaws, C. L.; Chiang, P.-Y. Chem. Eng. 1988, 95, 81.

(77) Colomina, M.; Jimenez, P.; Roux, M. V.; Turrion, C. An. Quim. 1986, 82, 126

(78) Cox, J. D.; Wagman, D. D.; Medvedev, V. A. CODATA Key Values for Thermodynamics; Hemisphere Publishing Corp.: New York, 1984.

(79) Chase, M. W., Jr. NIST-JANAF Themochemical Tables, 4th ed. J. Phys. Chem. Ref. Data 1998, Monogr. 9, 1-1951.

(80) Tsang, W. In Energetics of Organic Free Radicals; Martinho Simoes, J. A., Greenberg, A., Liebman, J. F., Eds.; Blackie Academic and Professional: London, U.K., 1996.

(81) Chickos, J. S.; Acree, W. E., Jr J. Phys. Chem. Ref. Data 2002, $31,537$.

JP7119334 